\title{
Prevalence and incidence of intra- and extrahepatic complications of NAFLD in patients with type 2 diabetes mellitus
}

\author{
Alessandro Mantovani ${ }^{1}$, Giorgia Beatrice ${ }^{1}$, Roberta Stupia $^{2}$, Andrea Dalbeni $^{2}$ \\ 'Section of Endocrinology, Diabetes and Metabolism, University and Azienda Ospedaliera Universitaria Integrata of Verona, \\ Verona 37126, Italy. \\ ${ }^{2}$ Section of General Medicine, Hypertension and Liver Unit, University and Azienda Ospedaliera Universitaria Integrata of \\ Verona, Verona 37126, Italy.
}

Correspondence to: Dr. Alessandro Mantovani, Section of Endocrinology, Diabetes and Metabolism, University and Azienda Ospedaliera Universitaria Integrata of Verona, Piazzale Stefani, 1, Verona 37126, Italy. E-mail: alessandro.mantovani@univr.it

How to cite this article: Mantovani A, Beatrice G, Stupia R, Dalbeni A. Prevalence and incidence of intra- and extrahepatic complications of NAFLD in patients with type 2 diabetes mellitus. Hepatoma Res 2020;6:78.

http://dx.doi.org/10.20517/2394-5079.2020.75

Received: 2 Aug 2020 First Decision: 24 Aug 2020 Revised: 12 Sep 2020 Accepted: 14 Oct 2020 Published: 6 Nov 2020

Academic Editor: Stefano Bellentani Copy Editor: Cai-Hong Wang Production Editor: Jing Yu

\begin{abstract}
Nonalcoholic fatty liver disease (NAFLD) is linked to abdominal obesity, insulin resistance and type 2 diabetes mellitus (T2DM). The association of NAFLD with T2DM is bidirectional. In fact, evidence suggests that abdominal obesity, T2DM and metabolic syndrome play a part in the development and progression of NAFLD. Alternatively, NAFLD is associated with an increased risk of having T2DM and metabolic syndrome. According to this background, it is unsurprising that patients with T2DM patients also have a higher prevalence of NAFLD than those with no T2DM, as well as an increased risk of developing liver-related and extrahepatic complications, mainly cardiovascular and renal diseases. Seeing the relationship of NAFLD with insulin resistance, obesity and T2DM, recent consensus proposes a change in nomenclature from NAFLD to metabolic associated fatty liver disease. In this review, we will discuss the prevalence and incidence of NAFLD (as detected by imaging techniques or liver biopsy) in patients with type T2DM with particular regard to hepatic and extrahepatic complications.
\end{abstract}

Keywords: Nonalcoholic fatty liver disease; NASH, metabolic associated fatty liver disease, diabetes, type 2 diabetes 


\section{INTRODUCTION}

In the last decades, it became clearly evident that nonalcoholic fatty liver disease (NAFLD) is associated with insulin resistance, abdominal obesity and type 2 diabetes mellitus(T2DM $)^{[1-5]}$. Specifically, the association between NAFLD and T2DM is intricate, and of note, it appears to be even bidirectional ${ }^{[1-5]}$. In fact, convincing data now indicate that abdominal obesity, T2DM and metabolic syndrome (MetS) can synergistically play a part in the development of NAFLD and its advanced forms ${ }^{[6,7]}$. Despite that, NAFLD is linked to a higher risk of T2DM and MetS, as well as to a poorer glycemic control in diabetic patients ${ }^{[6]}$. Based on these data, it is therefore unsurprising that patients with T2DM have an increased prevalence of NAFLD, when compared to those without T2DM, as well as a higher risk of developing serious liver-related [including nonalcoholic steatohepatitis (NASH), cirrhosis and hepatocellular carcinoma] and extrahepatic complications, such as cardiovascular and renal diseases [Figure 1$]^{[2,4,8]}$.

Since NAFLD, obesity, insulin resistance and T2DM are strictly linked, some researchers in this field have proposed and recommended a change in nomenclature from NAFLD to MAFLD, i.e., metabolic associated fatty liver disease ${ }^{[9-11]}$. This specific issue has not yet reached a consensus and is discussed in another article published in this journal.

In this review, we will discuss the prevalence and incidence of NAFLD (as detected by imaging techniques or liver biopsy) in patients with T2DM with particular regard to hepatic and extrahepatic complications.

\section{Search strategy and selection criteria}

In the PubMed-Medline database, we used the following terms: "fatty liver" or "NAFLD" or "NASH" and "diabetes mellitus" or "type 2 diabetes" (concluding research on the 30th July 2020). We did not apply any publication date or language restrictions. Finally, we used specific references of reviews to identify other relevant articles.

\section{Prevalence of NAFLD in patients with diabetes mellitus}

As reported in Table 1, in the last five years, several population-based studies and hospital-based studies have reported that in adult patients with T2DM the prevalence of NAFLD, as detected by imaging techniques or liver biopsy, ranged from $30 \%$ to $70 \%$ and from $50 \%$ to $70 \%$, respectively ${ }^{[12-75]}$. These data strongly support the assertion that NAFLD is much more frequent in patients with T2DM, when compared to the general population or other patient groups ${ }^{[1-4]}$. In particular, regarding the observational studies using liver ultrasound for the diagnosis of NAFLD, which is the recommended first-line imaging method for detecting hepatic steatosis in clinical practice ${ }^{[76]}$, the prevalence of NAFLD was approximately 70\%$75 \%$ in patients with T2DM, with however some exceptions. For instance, in a large cohort study involving nearly 5,500 South Korean patients with T2DM, Choe et al. ${ }^{[58]}$ documented that the prevalence of NAFLD was $46 \%$. In another population-based study of 8,571 Chinese hospitalized patients with T2DM, Guo et al. ${ }^{[24]}$ showed that the prevalence of NAFLD was approximately $51 \%$. Contrariwise, in a cross-sectional study including 222 Italian outpatients with T2DM, who were regularly seen at a specific diabetes clinic, Mantovani et al ${ }^{[45]}$ reported that the prevalence of NAFLD was more than $70 \%$. In addition, in a small study of 106 Australian patients with T2DM belonging a tertiary diabetes center, Williams et al. ${ }^{[22]}$ documented that the prevalence of NAFLD was even higher (84\%). Interestingly, in a recent cross-sectional study enrolling 137 patients with non-insulin-treated T2DM who underwent liver ultrasound and liver stiffness measurement (LSM) using vibration-controlled transient elastography (FibroScan ${ }^{\circ}$ ), Mantovani et al. ${ }^{[65]}$ showed that the proportion of T2DM patients with hepatic steatosis (on ultrasound) was $74 \%$ and that the proportion of individuals with significant liver fibrosis was approximately $18 \%$ with an LSM cut-off $\geq 7 \mathrm{kPa}$ and nearly $10 \%$ with an LSM cut-off $\geq 8.7 \mathrm{kPa}$.

The severity of NAFLD on ultrasound is usually graded using a 4-point scoring system: normal, mild, moderate and severe. In the literature, information regarding the prevalence of different grades of liver 


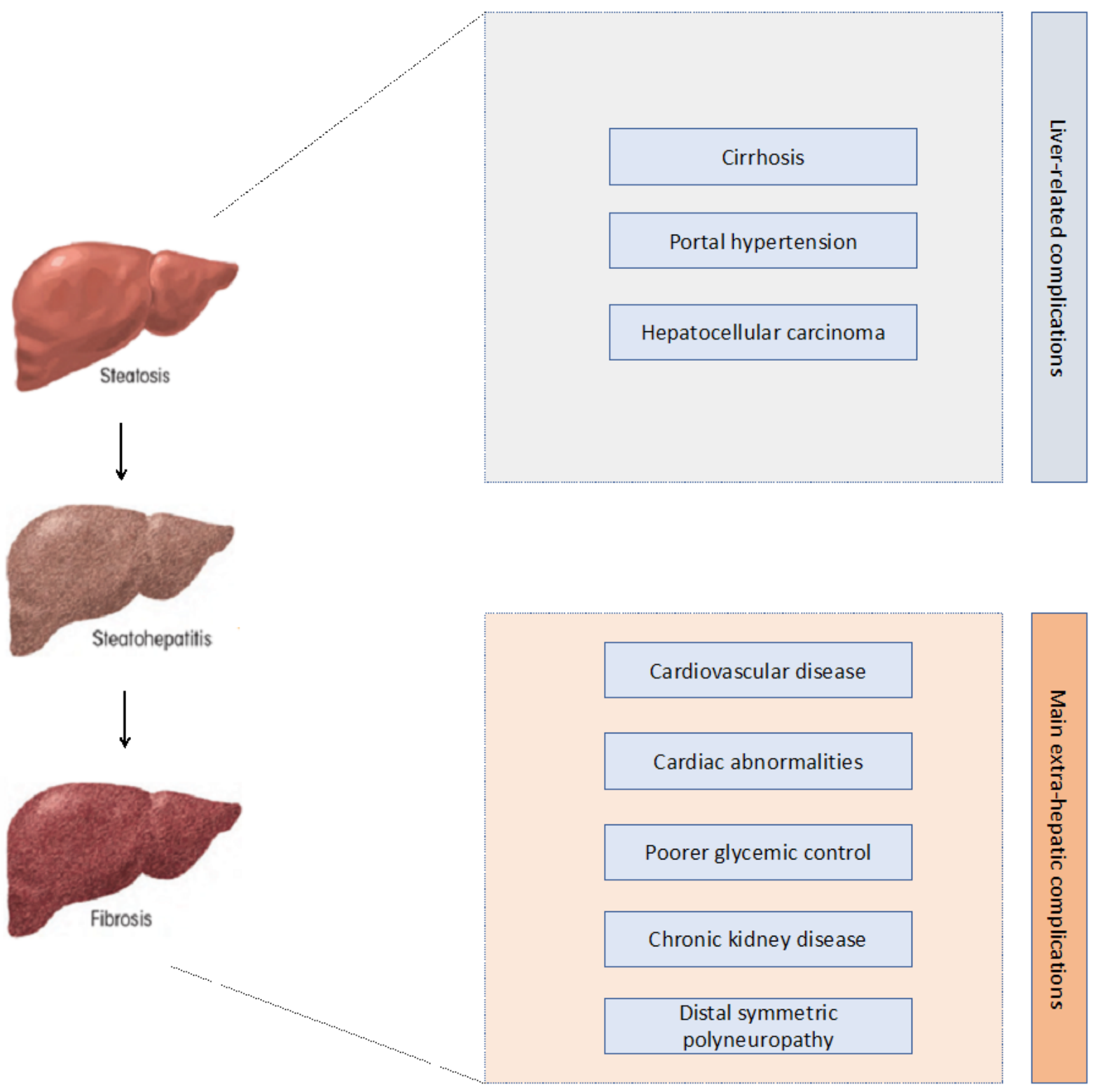

Figure 1. Main hepatic and extrahepatic complications associated with Nonalcoholic fatty liver disease in patients with type 2 diabetes mellitus

steatosis on ultrasound in patients with T2DM are also available ${ }^{[77,78]}$. For instance, in a cross-sectional study of 874 diabetic and non-diabetic patients, Wang et al. ${ }^{[77]}$ documented that the prevalence of T2DM among patients with mild liver steatosis (on ultrasound) was $7.5 \%$, whereas the percentage of T2DM individuals among those with moderate-to-severe liver steatosis was $23.4 \%(P<0.05)$.

These results clearly show that among the observational studies using liver ultrasound for the diagnosis of NALFD, the prevalence of NAFLD varies across different countries and clinical settings and it is influenced by different prevalence of obesity and degree of insulin resistance, as well as by the fact that ultrasound is an operator-dependent imaging technique. Indeed, the observational studies involving European or USA patients have reported a prevalence of NAFLD higher than that observed in the studies involving Asian patients. Additional factors that might explain these findings are different lifestyles (i.e., sedentary, physical inactivity), diets (i.e., high caloric diets, especially in the form of carbohydrates and 
Table 1. Principal studies evaluating the prevalence of NAFLD in patients with type 2 diabetes mellitus published in the last five years

\begin{tabular}{|c|c|c|}
\hline Author & Characteristics of study & Results \\
\hline Portillo-Sanchez et al. ${ }^{[12]}$ & $\begin{array}{l}103 \text { patients with T2DM from USA recruited from responses to local newspaper } \\
\text { advertisements or from people attending clinics in various USA medical Centers } \\
\text { Mean age: } 60 \text { years; mean BMI: } 33 \mathrm{~kg} / \mathrm{m}^{2} ; 87 \% \text { males }\end{array}$ & $\begin{array}{l}\text { Prevalence of NAFLD on } \\
\text { MRI was } 50 \%\end{array}$ \\
\hline Kwok et al. ${ }^{[13]}$ & $\begin{array}{l}\text { 1,918 patients with T2DM from Hong Kong, who attended diabetic complications } \\
\text { screening } \\
\text { Mean age } 60 \text { years; mean BMI } 33 \mathrm{~kg} / \mathrm{m}^{2} ; 87 \% \text { males }\end{array}$ & $\begin{array}{l}\text { Prevalence of NAFLD on } \\
\text { US was } 73 \%\end{array}$ \\
\hline Arab et $a l .{ }^{[14]}$ & $\begin{array}{l}133 \text { Chilean patients with T2DM invited by diabetologists and family physicians } \\
\text { for liver disease surveillance assessment } \\
\text { Mean age } 60 \text { years; mean BMI } 30 \mathrm{~kg} / \mathrm{m}^{2}, 47 \% \text { males }\end{array}$ & $\begin{array}{l}\text { Prevalence of NAFLD on } \\
\text { MRI was } 64 \%\end{array}$ \\
\hline Jung et $a .^{[15]}$ & $\begin{array}{l}186 \text { South Korean patients with T2DM admitted to the Endocrinology Division of } \\
\text { a university hospital } \\
\text { Mean age } 58 \text { years; mean BMI } 25 \mathrm{~kg} / \mathrm{m}^{2} ; 30 \% \text { Males }\end{array}$ & $\begin{array}{l}\text { Prevalence of NAFLD on } \\
\text { US was } 53 \%\end{array}$ \\
\hline Masarone et al. ${ }^{[16]}$ & $\begin{array}{l}63 \text { Italian patients with T2DM admitted to a tertiary center of internal medicine } \\
\text { and hepatology } \\
\text { Mean age } 57 \text { years, mean BMI } 34.4 \mathrm{~kg} / \mathrm{m}^{2}, 52.3 \% \text { males }\end{array}$ & $\begin{array}{l}\text { Prevalence of NAFLD on } \\
\text { liver biopsy was } 100 \%\end{array}$ \\
\hline Petit et al. ${ }^{[17]}$ & $\begin{array}{l}264 \text { French patients with T2DM screened prospectively at an endocrinology } \\
\text { department } \\
\text { Mean age } 60 \text { years, mean BMI } 34 \mathrm{~kg} / \mathrm{m}^{2}, 49 \% \text { males }\end{array}$ & $\begin{array}{l}\text { Prevalence of NAFLD on } \\
\text { MRI was } 63 \%\end{array}$ \\
\hline Wilman HR et al. ${ }^{[18]}$ & $\begin{array}{l}226 \text { British patients with T2DM who provided written informed consent to the } \\
\text { study in the United Kingdom Biobank imaging enhancement }\end{array}$ & $\begin{array}{l}\text { Prevalence of NAFLD on } \\
\text { MRI was } 50 \%\end{array}$ \\
\hline Doycheva et al. ${ }^{[19]}$ & $\begin{array}{l}100 \text { patients with T2DM from USA recruited via newspaper advertisement and } \\
\text { from primary care practices } \\
\text { Mean age } 60 \text { years, mean BMI } 31 \mathrm{~kg} / \mathrm{m}^{2}, 53 \% \text { males }\end{array}$ & $\begin{array}{l}\text { Prevalence of NAFLD on } \\
\text { MRI was } 65 \%\end{array}$ \\
\hline Ding et al. ${ }^{[20]}$ & $\begin{array}{l}\text { 1,648 Chinese patients with T2DM who lived in a specific district of Shangai } \\
\text { Mean age } 62 \text { years, mean BMI } 25 \mathrm{~kg} / \mathrm{m}^{2}, 49 \% \text { males }\end{array}$ & $\begin{array}{l}\text { Prevalence of NAFLD on } \\
\text { US was } 41.6 \%\end{array}$ \\
\hline Al Rifai et al. ${ }^{[21]}$ & $\begin{array}{l}517 \text { patients with T2DM of different ethnicity, from different areas of USA, } \\
\text { without known CVD at the time of enrollment }\end{array}$ & $\begin{array}{l}\text { Prevalence of NAFLD on } \\
\text { CT was } 28.4 \%\end{array}$ \\
\hline Williams et al. ${ }^{[22]}$ & $\begin{array}{l}106 \text { Australian patients with T2DM from a tertiary diabetes center } \\
\text { Mean age } 63 \text { years, mean BMI } 30 \mathrm{~kg} / \mathrm{m}^{2}, 61 \% \text { males }\end{array}$ & $\begin{array}{l}\text { Prevalence of NAFLD on } \\
\text { US was } 84 \%\end{array}$ \\
\hline Cusi et al. ${ }^{[23]}$ & $\begin{array}{l}385 \text { patients with T2DM from USA who had liver fat content evaluated by MRI } \\
\text { in four phase } 3 \text { studies of basal insulin peglispro (BIL) } \\
\text { Mean age } 60 \text { years, mean BMI } 32 \mathrm{~kg} / \mathrm{m}^{2}, 62 \% \text { males }\end{array}$ & $\begin{array}{l}\text { Prevalence of NAFLD on } \\
\text { MRI was } 75.6 \% \text { in insulin- } \\
\text { naïve T2DM patients, } \\
61.7 \% \text { in insulin-treated } \\
\text { T2DM patients }\end{array}$ \\
\hline Guo et al. ${ }^{[24]}$ & $\begin{array}{l}\text { 8,571 Chinese patients with T2DM hospitalized in the department of } \\
\text { endocrinology and metabolism of a hospital in Shangai } \\
\text { Mean age } 60 \text { years, mean BMI } 25 \mathrm{~kg} / \mathrm{m}^{2}, 56 \% \text { males }\end{array}$ & $\begin{array}{l}\text { Prevalence of NAFLD on } \\
\text { US was } 50.6 \%\end{array}$ \\
\hline Herath et al. ${ }^{[25]}$ & $\begin{array}{l}233 \text { Sri Lankan patients with T2DM followed up at a diabetes center } \\
\text { Mean age } 58 \text { years, mean BMI } 25 \mathrm{~kg} / \mathrm{m}^{2}, 47 \% \text { males }\end{array}$ & $\begin{array}{l}\text { Prevalence of NAFLD on } \\
\text { US was } 62.6 \%\end{array}$ \\
\hline Sberna et al. ${ }^{[26]}$ & $\begin{array}{l}179 \text { French patients with T2DM referred to a tertiary diabetes department } \\
\text { Mean age } 60 \text { years, mean BMI } 34 \mathrm{~kg} / \mathrm{m}^{2}, 47 \% \text { males }\end{array}$ & $\begin{array}{l}\text { Prevalence of NAFLD on } \\
\text { MRI was } 68.7 \%\end{array}$ \\
\hline Krishan et al. ${ }^{[27]}$ & $\begin{array}{l}100 \text { Indian patients with T2DM who underwent a routine health check-up } \\
\text { Mean age } 51 \text { years, mean BMI } 28 \mathrm{~kg} / \mathrm{m}^{2}, 82 \% \text { males }\end{array}$ & $\begin{array}{l}\text { Prevalence of NAFLD on } \\
\text { US was } 65 \%\end{array}$ \\
\hline Su et al. ${ }^{[28]}$ & $\begin{array}{l}445 \text { Chinese patients with T2DM who visited the hospital for evaluation or } \\
\text { treatment of T2DM } \\
\text { Mean age } 60 \text { years, mean BMI } 25 \mathrm{~kg} / \mathrm{m}^{2}, 53 \% \text { males }\end{array}$ & $\begin{array}{l}\text { Prevalence of NAFLD on } \\
\text { US was } 41.4 \%\end{array}$ \\
\hline Vanjiappan et al. ${ }^{[29]}$ & $\begin{array}{l}300 \text { Indian patients with T2DM attending the outpatient department of a } \\
\text { tertiary care hospital } \\
\text { Mean age } 54 \text { years, mean BMI } 25 \mathrm{~kg} / \mathrm{m}^{2}, 54 \% \text { males }\end{array}$ & $\begin{array}{l}\text { Prevalence of NAFLD on } \\
\text { US was } 61 \%\end{array}$ \\
\hline He et al. ${ }^{[30]}$ & $\begin{array}{l}331 \text { hospitalized patients from China with T2DM } \\
\text { Mean age } 57 \text { years, mean BMI } 26 \mathrm{~kg} / \mathrm{m}^{2}, 50 \% \text { males }\end{array}$ & $\begin{array}{l}\text { Prevalence of NAFLD on } \\
\text { US was } 63 \%\end{array}$ \\
\hline Kabir et al. ${ }^{[31]}$ & $\begin{array}{l}258 \text { Bangladeshi patients with T2DM included in this observational study in the } \\
\text { department of medicine of a hospital in Bangladesh }\end{array}$ & $\begin{array}{l}\text { Prevalence of NAFLD on } \\
\text { US was } 64.7 \%\end{array}$ \\
\hline Lai et al. ${ }^{[32]}$ & $\begin{array}{l}557 \text { Malaysian patients with T2DM attending the diabetes clinic of a university } \\
\text { hospital } \\
\text { Mean age } 61 \text { years, } 41 \% \text { males }\end{array}$ & $\begin{array}{l}\text { Prevalence of NAFLD on } \\
\text { US was } 72.4 \%\end{array}$ \\
\hline Hashimoto et al. ${ }^{[33]}$ & $\begin{array}{l}145 \text { Japanese patients with T2DM recruited from the outpatient clinic of a } \\
\text { university hospital in Kyoto } \\
\text { Mean age } 66 \text { years, mean BMI } 25 \mathrm{~kg} / \mathrm{m}^{2}, 55 \% \text { males }\end{array}$ & $\begin{array}{l}\text { Prevalence of NAFLD on } \\
\text { US was } 67 \%\end{array}$ \\
\hline Zou et al. ${ }^{[34]}$ & $\begin{array}{l}2646 \text { Chinese patients with T2DM recruited from a local health examination } \\
\text { center for diabetes, newly diagnosed diabetics or with a previous diagnosis of } \\
\text { T2DM } \\
\text { Mean age } 61 \text { years, mean BMI } 26 \mathrm{~kg} / \mathrm{m}^{2}, 42 \% \text { males }\end{array}$ & $\begin{array}{l}\text { Prevalence of NAFLD on } \\
\text { US was } 50.9 \%\end{array}$ \\
\hline
\end{tabular}




Afolabi et al. ${ }^{[35]}$
Moh Moh et al. ${ }^{[36]}$
Cosma et al. ${ }^{[37]}$

Almobarak et al. ${ }^{[38]}$

Yan et al. ${ }^{[39]}$

Alsabaani et al. ${ }^{[40]}$

Gutierrez-Buey et al. ${ }^{[41]}$

Zawdie et al. ${ }^{[42]}$

Dvorak et al. ${ }^{[43]}$

Hua et al. ${ }^{[44]}$

Mantovani et al. ${ }^{[45]}$

Olusanya et al. ${ }^{[46]}$

Chang et al. ${ }^{[47]}$

Zhao et al. ${ }^{[48]}$

Zhang et al. ${ }^{[49]}$

Johansen et al. ${ }^{[50]}$

Fan et al. ${ }^{[51]}$

García Díaz et al. ${ }^{[52]}$

Demir et al. ${ }^{[53]}$

Petit et al. ${ }^{[54]}$

Zhao et al. ${ }^{[55]}$

Mantovani et al. ${ }^{[56]}$

Barchetta et al. ${ }^{[57]}$

Choe et al. ${ }^{[58]}$

Silaghi et al. ${ }^{[59]}$
80 Nigerian patients with T2DM recruited from the endocrinology clinic of a hospital

Mean age 61 years, mean BMI $26 \mathrm{~kg} / \mathrm{m}^{2}, 38 \%$ males

172 South Korean patients with T2DM who were admitted for glucose control to the endocrinology division of a university hospital

Mean age 57 years, mean BMI $25 \mathrm{~kg} / \mathrm{m}^{2}, 50 \%$ males

60 Italian patients with T2DM enrolled in the study during their routine visit at a diabetes Centre

Mean age 65 years, BMI $32 \mathrm{~kg} / \mathrm{m}^{2}, 42 \%$ males

167 Sudanese patients with T2DM recruited from the outpatient of a diabetic center

$87 \%$ subjects were aged $40-70$ years, $8 \%$ subjects $>70$ years and $5 \%$ subjects

$<40$ years, mean $46.7 \%$ males

212 Chinese patients with T2DM recruited from a metabolic disease hospital Mean age 54 years, mean BMI $27 \mathrm{~kg} / \mathrm{m}^{2}, 57 \%$ males

245 Arab patients with T2DM recruited from primary healthcare centers Mean age 57 years, $66 \%$ males

56 Spanish patients with well-controlled T2DM ( HbAc1 < 7\%)

Mean age 64 years, mean BMI $28 \mathrm{~kg} / \mathrm{m}^{2}, 80 \%$ males

96 Ethiopian patients with T2DM attending a diabetic clinic

Mean BMI $23 \mathrm{~kg} / \mathrm{m}^{2}, 47 \%$ males

180 Czech patients with T2DM

Mean age 64 years, mean BMI $32 \mathrm{~kg} / \mathrm{m}^{2}, 63 \%$ males

1,037 Chinese patients with T2DM who visited for different medical reasons a specific hospital in the city of Nanjing were enrolled Mean age 57 years, mean BMI $24 \mathrm{~kg} / \mathrm{m}^{2}, 59 \%$ males

222 Italian patients with T2DM, who regularly attended a specific diabetes clinic Mean age 67 years, mean BMI $29 \mathrm{~kg} / \mathrm{m}^{2}, 70 \%$ males

168 Nigerian patients with T2DM evaluated at an endocrine clinic

Mean age 53 years, mean BMI $28 \mathrm{~kg} / \mathrm{m}^{2}, 35 \%$ males

97 Chinese patients with T2DM who agreed to participate in the study

Mean age 47 years, mean BMI $26 \mathrm{~kg} / \mathrm{m}^{2}, 71 \%$ males

2,042 Chinese patients with T2DM hospitalized in an endocrinology and metabolism department

Mean age 60 years, mean BMI $25 \mathrm{~kg} / \mathrm{m}^{2}, 47 \%$ males

175 Chinese patients with newly diagnosed T2DM enrolled in this study from the endocrinology department of a hospital in Wuhan

Mean age 52 years, mean BMI $24 \mathrm{~kg} / \mathrm{m}^{2}, 56 \%$ males

120 Danish patients with T2DM recruited at the diabetes outpatient clinic at a university hospital

Mean age 63 years, mean BMI $30 \mathrm{~kg} / \mathrm{m}^{2}, 73 \%$ males

541 Chinese patients with T2DM recruited from a department of endocrinology and metabolism

Mean age 58 years, mean BMI $25 \mathrm{~kg} / \mathrm{m}^{2}, 50 \%$ Males

58 Spanish patients with T2DM whose diabetes was treated in any medical center of Lanzarote

Mean age 55 years, mean BMI $31 \mathrm{~kg} / \mathrm{m}^{2}, 61 \%$ males

124 Turkish patients with T2DM invited to undergo a liver US for screening Mean age 53 years, mean BMI $33 \mathrm{~kg} / \mathrm{m}^{2}, 37 \%$ males

308 French patients screened at an endocrinology department to participate in the study to determine whether a specific polymorphism was involved in the development of NAFLD

Mean age 60 years, mean BMI $34 \mathrm{~kg} / \mathrm{m}^{2}, 51 \%$ males

629 Chinese patients with T2DM enrolled to evaluate their liver conditions

Mean age 44 years, mean BMI $26 \mathrm{~kg} / \mathrm{m}^{2}, 91 \%$ males

330 Italian patients with T2DM

who regularly attended a diabetes clinic and

had undergone a first 24-hour Holter monitoring for clinical reasons

Mean age 70 years, mean BMI $29 \mathrm{~kg} / \mathrm{m}^{2}, 65 \%$ males

62 Italian patients with T2DM referred to diabetes outpatient clinics who

underwent clinical work-up

Mean age 59 years, mean BMI $30 \mathrm{~kg} / \mathrm{m}^{2}, 72 \%$ males

5,507 South Korean patients with T2DM diagnosed at the Huh's Diabetes

Center in Seoul, who underwent an abdominal US

Mean age 57 years, mean BMI $24 \mathrm{~kg} / \mathrm{m}^{2}, 51 \%$ males

336 Romanian patients with T2DM who regularly attended diabetes evaluation

in the same clinic

Mean age 56 years, mean BMI $32 \mathrm{~kg} / \mathrm{m}^{2}$
Prevalence of NAFLD on

US was $68.8 \%$

Prevalence of NAFLD on US was $51 \%$

Prevalence of NAFLD on US was $88 \%$

Prevalence of NAFLD on US was $50.3 \%$

Prevalence of NAFLD on US was $67.5 \%$

Prevalence of NAFLD on US was $72.8 \%$

Prevalence of NAFLD on US or CT was $73.2 \%$

Prevalence of NAFLD on US was $73 \%$

Prevalence of NAFLD on US was $79 \%$

Prevalence of NAFLD on US was $56.3 \%$

Prevalence of NAFLD on US was $71.2 \%$

Prevalence of NAFLD on US was $16.7 \%$

Prevalence of NAFLD on US was $69 \%$

Prevalence of NAFLD on US was $40.2 \%$

Prevalence of NAFLD on US was $53 \%$

Prevalence of NAFLD on MRI was $48 \%$

Prevalence of NAFLD on US was $56.6 \%$

Prevalence of NAFLD on US was $57.8 \%$

Prevalence of NAFLD on US was $94.3 \%$

Prevalence of NAFLD on MRI was $65.2 \%$

Prevalence of NAFLD on US was $67.7 \%$

Prevalence of NAFLD on US was $72.1 \%$

Prevalence of NAFLD on MRI was $56.5 \%$

Prevalence of NAFLD on US was $46.4 \%$

Prevalence of NAFLD on US was $86 \%$ 


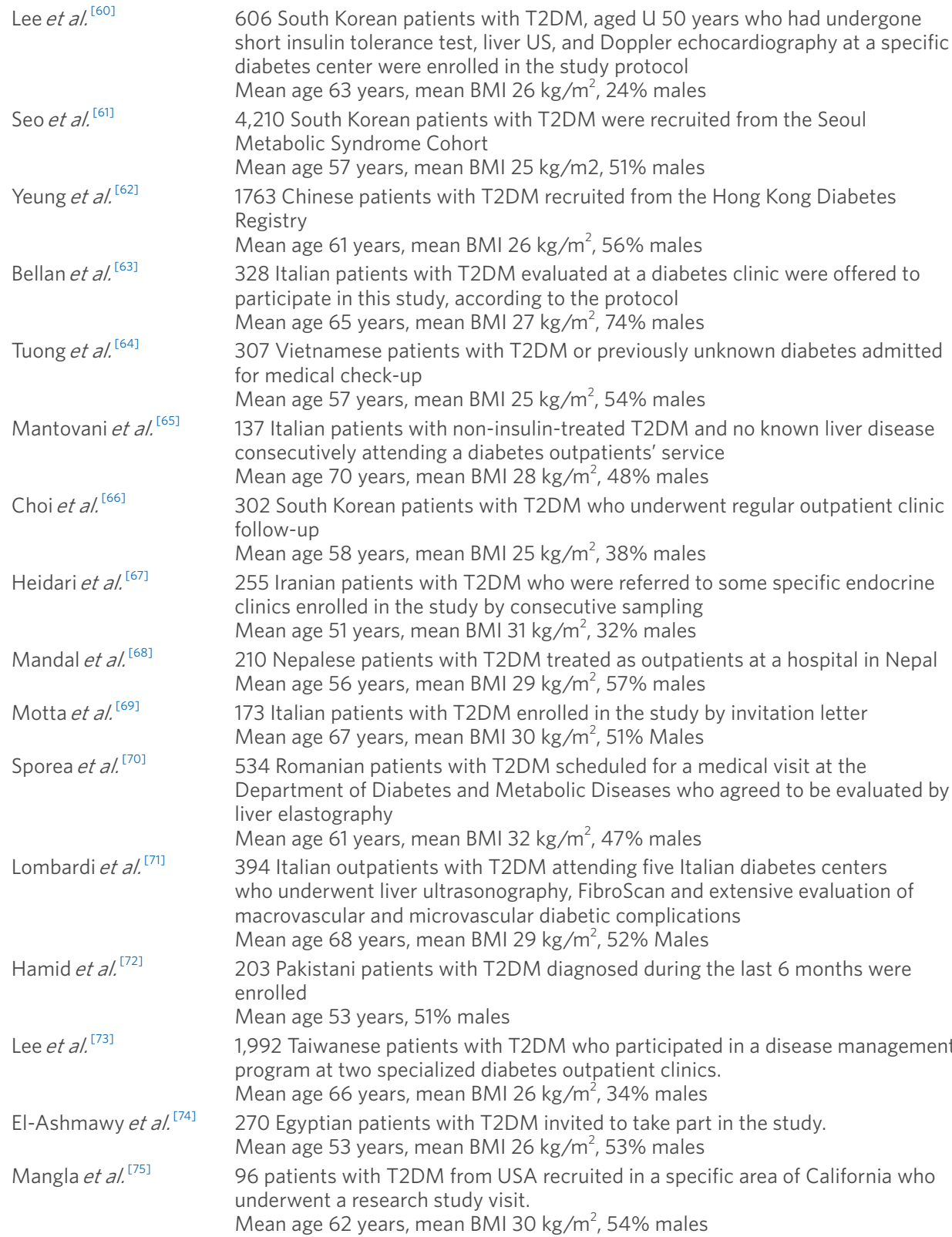

606 South Korean patients with T2DM, aged U 50 years who had undergone short insulin tolerance test, liver US, and Doppler echocardiography at a specific diabetes center were enrolled in the study protocol Mean age 63 years, mean BMI $26 \mathrm{~kg} / \mathrm{m}^{2}, 24 \%$ males

4,210 South Korean patients with T2DM were recruited from the Seoul Metabolic Syndrome Cohort

Mean age 57 years, mean BMI $25 \mathrm{~kg} / \mathrm{m} 2,51 \%$ males

1763 Chinese patients with T2DM recruited from the Hong Kong Diabetes Registry

Mean age 61 years, mean BMI $26 \mathrm{~kg} / \mathrm{m}^{2}, 56 \%$ males

328 Italian patients with T2DM evaluated at a diabetes clinic were offered to participate in this study, according to the protocol Mean age 65 years, mean BMI $27 \mathrm{~kg} / \mathrm{m}^{2}, 74 \%$ males

307 Vietnamese patients with T2DM or previously unknown diabetes admitted for medical check-up

Mean age 57 years, mean BMI $25 \mathrm{~kg} / \mathrm{m}^{2}, 54 \%$ males

37 Italian patients with non-insulin-treated T2DM and no known liver disease consecutively attending a diabetes outpatients' service Mean age 70 years, mean BMI $28 \mathrm{~kg} / \mathrm{m}^{2}, 48 \%$ males

302 South Korean patients with T2DM who underwent regular outpatient clinic follow-up

Mean age 58 years, mean BMI $25 \mathrm{~kg} / \mathrm{m}^{2}, 38 \%$ males

255 Iranian patients with T2DM who were referred to some specific endocrine clinics enrolled in the study by consecutive sampling Mean age 51 years, mean BMI $31 \mathrm{~kg} / \mathrm{m}^{2}, 32 \%$ males

210 Nepalese patients with T2DM treated as outpatients at a hospital in Nepal Mean age 56 years, mean BMI $29 \mathrm{~kg} / \mathrm{m}^{2}, 57 \%$ males

173 Italian patients with T2DM enrolled in the study by invitation letter Mean age 67 years, mean BMI $30 \mathrm{~kg} / \mathrm{m}^{2}, 51 \%$ Males

534 Romanian patients with T2DM scheduled for a medical visit at the Department of Diabetes and Metabolic Diseases who agreed to be evaluated by liver elastography

Mean age 61 years, mean BMI $32 \mathrm{~kg} / \mathrm{m}^{2}, 47 \%$ males

394 Italian outpatients with T2DM attending five Italian diabetes centers who underwent liver ultrasonography, FibroScan and extensive evaluation of macrovascular and microvascular diabetic complications

Mean age 68 years, mean BMI $29 \mathrm{~kg} / \mathrm{m}^{2}, 52 \%$ Males

203 Pakistani patients with T2DM diagnosed during the last 6 months were enrolled

Mean age 53 years, $51 \%$ males

1,992 Taiwanese patients with T2DM who participated in a disease management program at two specialized diabetes outpatient clinics.

Mean age 66 years, mean BMI $26 \mathrm{~kg} / \mathrm{m}^{2}, 34 \%$ males

270 Egyptian patients with T2DM invited to take part in the study.

Mean age 53 years, mean BMI $26 \mathrm{~kg} / \mathrm{m}^{2}, 53 \%$ males

96 patients with T2DM from USA recruited in a specific area of California who underwent a research study visit.

Mean age 62 years, mean BMI $30 \mathrm{~kg} / \mathrm{m}^{2}, 54 \%$ males

Prevalence of NAFLD on US was $58.6 \%$

Prevalence of NAFLD on US was $30.4 \%$

Prevalence of NAFLD on US was $53.2 \%$

Prevalence of NAFLD on US was $59.5 \%$

Prevalence of NAFLD on US was $73.3 \%$

Prevalence of NAFLD on US was $73.7 \%$

Prevalence of NAFLD on US was $62 \%$

Prevalence of NAFLD on US was $86.7 \%$

Prevalence of NAFLD on US was $55.7 \%$

Prevalence of NAFLD on US was $24.9 \%$

Prevalence of NAFLD of US was $76 \%$

Prevalence of NAFLD on US was $89 \%$

Prevalence of NAFLD on US was $71.9 \%$

Prevalence of NAFLD on US was $55.9 \%$

Prevalence of NAFLD on US was $73.3 \%$

Prevalence of NAFLD on MRI was $65.6 \%$

BMI: body mass index; CT: computed tomography; MRI: magnetic resonance imaging; NAFLD: nonalcoholic fatty liver disease; T2DM: type 2 diabetes; US: ultrasound

fats) and genetic factors ${ }^{[1-4]}$. It is known that overeating, physical inactivity and scarce aerobic fitness are associated with reduced triglyceride export, increased de novo lipogenesis and increased fatty acid uptake in the liver ${ }^{[79,80]}$. All these elements may lead to additional hepatic lipid storage with relevant metabolic consequences ${ }^{[79,80]}$. Regarding genetic factors, NAFLD congregates in families with specific variants, such as patatin-like phospholipase domain-containing 3 gene (PNPLA3) and transmembrane 6 superfamily member $2\left(\mathrm{TM}_{6} \mathrm{SF}_{2}\right)^{[81]}$. One of the main genetic variants associated with NAFLD is a mutation [I148M] in PNPLA ${ }^{[81]}$. PNPLA3 plays a key role in hepatic fat accumulation in GG homozygous individuals ${ }^{[81]}$. In addition, these patients are at higher risk of developing the more severe forms of NAFLD, independent of $\mathrm{T}_{2} \mathrm{DM}^{[81]}$. Interestingly, the single variant in the PNPLA3 gene (I148M) has the highest prevalence in Hispanics, followed by non-Hispanic whites, Asians, and African Americans ${ }^{[81]}$. 
Regarding the observational studies using magnetic resonance imaging (MRI) for the diagnosis of NAFLD, it is possible to observe that the prevalence of NAFLD ranges from $50 \%$ to $70 \%$. For instance, in a study enrolling 103 patients with T2DM and normal plasma aminotransferase levels, Portillo-Sanchez et al. ${ }^{[12]}$ reported that the prevalence of NAFLD was approximately 50\%. Moreover, in that study, the authors reported a high prevalence of NASH in a subgroup of patients who underwent liver biopsy ${ }^{[12]}$. Indeed, approximately $55 \%$ of patients with NAFLD on MRI had histological features suggestive of NASH ${ }^{[12]}$. These data strongly support the assertion that patients with T2DM have a high risk of developing severe forms of NAFLD, such as NASH and advanced fibrosis, which are the histological features more closely associated with hepatic and extrahepatic complications ${ }^{[1-4]}$. Also in this regard, Bazick et al ${ }^{[82]}$ found in an observational study involving approximately 350 patients with T2DM who underwent liver biopsy, that the prevalence of NASH and advanced fibrosis was 69 and $41 \%$, respectively. In another study including 108 patients with biopsy-proven NAFLD, McPherson et al. ${ }^{[83]}$ reported that approximately $80 \%$ of patients who had had progression in fibrosis were diabetics, whereas among non-progressor patients only $25 \%$ had diabetes mellitus. The association between T2DM and the more severe forms of NAFLD was also reported by Loomba et al. ${ }^{[84]}$ in an observational study enrolling 1,069 T2DM patients with biopsy-proven NAFLD, documenting a significant association between history of diabetes mellitus, NASH and advanced fibrosis, even after adjusting for age, sex, body mass index, ethnicity, and presence of metabolic syndrome. Moreover, in a retrospective analysis of 235 patients with biopsy-proven NAFLD with and without T2DM, Puchakayala et al ${ }^{[85]}$ documented that among T2DM patients with NAFLD, the prevalence of advanced fibrosis and ballooning were significantly greater as compared to patients with NAFLD but without T2DM. Interestingly and importantly, in the multivariate regression analysis, T2DM was associated with NASH and fibrosis in all patients with NAFLD ${ }^{[85]}$.

These data were additionally replicated in a recent meta-analysis by Younossi et al ${ }^{[86]}$ including 80 observational studies for a total of nearly 49,500 individuals with T2DM (mean age: 58 years; mean body mass index: $28 \mathrm{~kg} / \mathrm{m}^{2}$; percentage of men: $53 \%$ ). In this meta-analysis, the authors found that the overall prevalence of NAFLD was approximately 55\%, the global prevalence of NASH was $37 \%$, and the prevalence of advanced fibrosis was $17 \%{ }^{[86]}$.

Importantly, the coexistence of NAFLD and T2DM is also associated with a poorer cardiometabolic profile in terms of glycemic control, atherogenic dyslipidemia and hypertension ${ }^{[4,87]}$. Coexisting NAFLD and $\mathrm{T} 2 \mathrm{DM}$ may also increase insulin requirement in T2DM patients treated with basal bolus insulin regimen ${ }^{[87]}$.

\section{NAFLD and risk of incident T2DM}

Several epidemiological studies have documented that NAFLD, as detected by ultrasound, is associated with an increased risk of incident T2DM, even after adjustment for many metabolic confounders, such as age, sex, body mass index, smoking status, alcohol intake, physical activity, family history of diabetes, lipids and insulin resistance ${ }^{\left[88^{-106]}\right.}$. This finding was also replicated by a 2018 meta-analysis including 19 cohort studies for a total of approximately 300,000 individuals (30\% with NAFLD) and nearly 16,000 cases of incident diabetes over a median of 5 years ${ }^{[107]}$. In fact, in this study, Mantovani et al. ${ }^{[107]}$ reported that patients with NAFLD had a higher risk of incident diabetes mellitus when compared to those with no liver involvement [random-effects hazard ratio (HR) 2.22, 95\% confidence interval 1.84-2.60; $\mathrm{I}^{2}=79 \%$ ]. In addition, in that study, patients with more "severe" NAFLD were also more likely to develop incident diabetes mellitus ${ }^{[107]}$. More recently, a 2020 meta-analysis of nearly 500,000 individuals reported similar results ${ }^{[108]}$.

Few studies have assessed the risk of incident T2DM in relation to the modification of NAFLD status over time $e^{[7,97,109,110]}$. For instance, in a retrospective longitudinal study including approximately 13,000 Korean individuals followed for 5 years, Sung et al. ${ }^{[109]}$ documented that alterations in fatty liver content (on 
ultrasound) over time was associated with changeable risks of incident T2DM. Recently, in an observational study including 2,726 patients in which NAFLD status change was assessed by serial abdominal ultrasonography and fatty liver index (FLI) during a follow-up of 10 years, Cho et al ${ }^{[110]}$ documented that the progression and regression of NAFLD were respectively associated with positive and negative risk of incident diabetes mellitus. These findings additionally corroborate the assumption that NAFLD is a modifiable trigger factor associated with the progression to the advanced stages of diabetes mellitus ${ }^{[111]}$.

\section{Sex as key modulator of NAFLD in patients with T2DM}

Experimental data and computer modeling now indicate that female and male livers may be metabolically distinct with specific and different regulators ${ }^{[112,113]}$. In particular, accumulating data suggest that the prevalence and severity of NAFLD tend to be greater in men as compared to women during the reproductive age. Conversely, after menopause, the prevalence of NAFLD tends to be higher in women, thereby indicating a potential protective role of the estrogens ${ }^{[113]}$. However, most observational studies available so far, including those conducted in patients with T2DM, did not have specific statistical analyses considering sex differences or sex hormones/menopausal status as potential modifiers. In a 2020 metaanalysis of 33 cohort studies, Mantovani et al. ${ }^{[108]}$ did not observe an effect of sex on the relationship between NAFLD and risk of incident T2DM, but this may partly reflect the characteristics of the eligible observational studies. Along with other authors ${ }^{[113]}$, we strongly believe that future observational studies should have sex-specific analyses.

\section{Liver complications in NAFLD patients with diabetes mellitus}

Liver involvement in patients with $\mathrm{T} 2 \mathrm{DM}$ is recognized in the form of simple steatosis, nonalcoholic steatohepatitis (NASH), advanced fibrosis, cirrhosis, hepatocellular carcinoma, glycogenic hepatopathy and hepatic arteriolosclerosis ${ }^{[114]}$. That said, some histological analysis suggests that simple steatosis is a benign condition, while NASH with different degrees of hepatic fibrosis is closely associated with liver-related morbidity and mortality. As previously mentioned, T2DM patients have a greater prevalence of NASH and advanced fibrosis when compared to the general adult population ${ }^{[114]}$. In addition, many observational studies have clearly demonstrated that $\mathrm{T} 2 \mathrm{DM}$, along with obesity and severe degrees of insulin resistance, is one of the main clinical risk factors implicated in the progression of NAFLD to NASH, advanced fibrosis or cirrhosis ${ }^{[1,2,4]}$. Conversely, it is also reported that the presence of NAFLD may also adversely influence the prognosis of diabetes ${ }^{[1,2,4]}$. Among various observational studies ${ }^{[115-127]}$ published so far [Table 2], the Verona Diabetes Study was one of first observational studies demonstrating that the risk of mortality from liver causes was higher in a large cohort of T2DM patients when compared to the general population ${ }^{[115]}$. These findings were subsequently replicated in other case-control studies. For instance, in a retrospective study that used the administrative database of the Veneto region, Zoppini et al. ${ }^{[16]}$ observed that Italian T2DM individuals had a roughly 3 -fold higher risk of dying from chronic liver diseases due to a nonvirus and non-alcohol-related etiology. In another community-based cohort study involving nearly 340 T2DM patients, Adams et al. ${ }^{[117]}$ showed that the presence of NAFLD, as detected by imaging or biopsy, was associated with a higher risk of all-cause mortality (mainly due to cardiovascular disease, malignancy and liver-related complications) during a mean follow-up of 11 years.

An association between T2DM and liver cirrhosis is also currently known. In patients with cirrhosis, indeed, diabetes mellitus can be due to the presence of T2DM or as a direct consequence of liver insufficiency (namely hepatogenous diabetes mellitus) ${ }^{[114]}$. In this context, several observational studies have documented an elevated prevalence of cirrhosis in patients with T2DM and NAFLD, especially if they are older or have cardiovascular complications ${ }^{[114,118]}$. Cirrhosis is also associated with reduced hepatic mass and portosystemic shunts; two conditions able to alter insulin clearance, thereby contributing to systemic insulin resistance ${ }^{[119]}$. In addition, cirrhosis is associated with increased levels of hypoxia-inducible factors and advanced glycation end products, which play a role in the development of $\mathrm{T}_{2} \mathrm{DM}^{[119,120]}$. $\mathrm{T} 2 \mathrm{DM}$ is an 
Table 2. Principal observational studies that assessed the association between NAFLD and risk of liver-related disease and extrahepatic complications (cardiovascular diseases)

\begin{tabular}{|c|c|c|c|c|c|}
\hline Author & Study characteristics & Complication & $\begin{array}{l}\text { NAFLD } \\
\text { diagnosis }\end{array}$ & Results & Country \\
\hline De Marco et al. ${ }^{[115]}$ & $\begin{array}{l}\text { Population-based study: } \\
\text { 7,148 T2DM patients } \\
(3,366 \text { men and 3,782 } \\
\text { women) followed for a } \\
\text { period of } 5 \text { years }\end{array}$ & Mortality & US & $\begin{array}{l}\text { The highest SMRs in the } \\
\text { diabetic cohort were for } \\
\text { diabetes, liver cirrhosis and } \\
\text { cardiovascular diseases }\end{array}$ & Italy \\
\hline Zoppini et al. ${ }^{[116]}$ & $\begin{array}{l}\text { Retrospective study: } \\
\text { 167,621 T2DM patients, } \\
\text { aged } 30-89 \text { years ( } 54.6 \% \\
\text { men), followed from } 2008 \\
\text { to } 2010\end{array}$ & Mortality & US & $\begin{array}{l}\text { T2DM patients had a higher } \\
\text { risk of dying from chronic } \\
\text { liver diseases, in particular } \\
\text { NAFLD }\end{array}$ & Italy \\
\hline Adams et al. ${ }^{[117]}$ & $\begin{array}{l}\text { Community-based study: } \\
337 \text { T2DM patients } \\
\text { from Olmsted County, } \\
\text { Minnesota, } \\
\text { followed for } 11 \text { years; } 116 \text { of } \\
\text { them had NAFLD }\end{array}$ & Mortality & US & $\begin{array}{l}\text { Overall mortality was } \\
\text { significantly associated } \\
\text { with a diagnosis of NAFLD, } \\
\text { presence of ischemic heart } \\
\text { disease and duration of } \\
\text { diabetes }\end{array}$ & USA \\
\hline Bertot et al. ${ }^{[119]}$ & $\begin{array}{l}\text { Prospective study: } 284 \\
\text { patients ( } 53 \% \text { with } \\
\text { T2DM, 15\% with cirrhosis) } \\
\text { followed up for a median } \\
\text { period of } 51 \text { months }\end{array}$ & $\begin{array}{l}\text { Death/transplantation, } \\
\text { decompensation, HCC }\end{array}$ & $\begin{array}{l}\text { Biopsy, } \\
\text { Hepascore, } \\
\text { NAFLD fibrosis } \\
\text { score (NFS), } \\
\text { APRI and FIB-4 }\end{array}$ & $\begin{array}{l}\text { T2DM patients had a } \\
\text { greater risk of liver-related } \\
\text { death/transplantation } \\
\text { (HR 3.4, 95\% Cl: } 1.2-9.1) \\
\text { decompensation (HR 4.7, } \\
95 \% \mathrm{Cl}: 2.0-11.3 \text { ) and } \mathrm{HCC} \\
(\mathrm{HR} 2.9,95 \% \mathrm{Cl}: 1.2-7.3)\end{array}$ & Australia \\
\hline Sanyal et al. ${ }^{[121]}$ & $\begin{array}{l}\text { Prospective study: using a } \\
\text { health care claims database } \\
\text { from Thomas Reuters } \\
\text { covering } 18 \text { million lives } \\
\text { yearly and all USA census } \\
\text { regions from } 2002 \text { to } \\
2008,4,406 \text { HCC patients } \\
\text { were identified }\end{array}$ & HCC & $\begin{array}{l}\text { Radiological } \\
\text { imaging }\end{array}$ & $\begin{array}{l}\text { The incidence of HCC in the } \\
\text { database was } 0.4 \text { per } 1,000 \\
\text { persons. NAFLD/NASH } \\
\text { ( } 59 \% \text { ) and T2DM ( } 36 \% \text { ), } \\
\text { along with hepatitis C virus } \\
\text { infection ( } 22 \%) \text {, were the } \\
\text { main etiologic risk factors } \\
\text { associated with HCC }\end{array}$ & USA \\
\hline Ertle et al. ${ }^{[122]}$ & $\begin{array}{l}\text { Cross-sectional study: } 162 \\
\text { adults with HCC enrolled } \\
\text { between February } 2007 \\
\text { and March } 2008\end{array}$ & $\mathrm{HCC}$ & $\begin{array}{l}\text { Radiological } \\
\text { imaging }\end{array}$ & $\begin{array}{l}\text { Patients with NAFLD/ } \\
\text { NASH-associated HCC } \\
\text { exhibited a higher prevalence } \\
\text { of T2DM, hypertension, } \\
\text { dyslipidemia, coronary } \\
\text { artery disease, when } \\
\text { compared to non-NAFLD/ } \\
\text { NASH-HCC }\end{array}$ & Germany \\
\hline Targher et al. ${ }^{[123]}$ & $\begin{array}{l}\text { Cross-sectional study: } \\
\text { 2,893 T2DM outpatients; } \\
\text { 1,974 had NAFLD }\end{array}$ & $\begin{array}{l}\text { Coronary heart disease, } \\
\text { myocardial infarction, } \\
\text { angina, cerebrovascular } \\
\text { disease and peripheral } \\
\text { vascular disease }\end{array}$ & US & $\begin{array}{l}\text { NAFLD was associated } \\
\text { with a greater risk of } \\
\text { prevalent CVD, independent } \\
\text { of classical risk factors, } \\
\text { glycemic control, } \\
\text { medications and metabolic } \\
\text { syndrome features }\end{array}$ & Italy \\
\hline Cassidy et al. ${ }^{[124]}$ & $\begin{array}{l}\text { Case-control study: } 19 \\
\text { adults with T2DM, } 19 \\
\text { adults with NAFLD and } 19 \\
\text { healthy controls }\end{array}$ & $\begin{array}{l}\text { Cardiac structure, function } \\
\text { and metabolism }\end{array}$ & $\begin{array}{l}\text { Magnetic } \\
\text { resonance } \\
\text { imaging }\end{array}$ & $\begin{array}{l}\text { Changes in cardiac structure } \\
\text { were evident in adults with } \\
\text { T2DM and NAFLD }\end{array}$ & $\begin{array}{l}\text { United } \\
\text { Kingdom }\end{array}$ \\
\hline Mantovani et al. ${ }^{[45]}$ & $\begin{array}{l}\text { Cross-sectional study: } 222 \\
\text { T2DM outpatients with no } \\
\text { previous history of CVD }\end{array}$ & Left ventricular dysfunction & US & $\begin{array}{l}\text { NAFLD was associated } \\
\text { with an increased risk of } \\
\text { mild and/or moderate } \\
\text { left ventricular diastolic } \\
\text { dysfunction }\end{array}$ & Italy \\
\hline Mantovani et al. ${ }^{[125]}$ & $\begin{array}{l}\text { Cross-sectional study: } \\
247 \text { consecutive T2DM } \\
\text { outpatients with no } \\
\text { previous history of heart } \\
\text { failure, valvular heart } \\
\text { diseases and hepatic } \\
\text { diseases }\end{array}$ & $\begin{array}{l}\text { Cardiac calcification on } \\
\text { echocardiography }\end{array}$ & US & $\begin{array}{l}\text { NAFLD was independently } \\
\text { associated with cardiac } \\
\text { calcification both aortic and } \\
\text { mitral valves }\end{array}$ & Italy \\
\hline
\end{tabular}




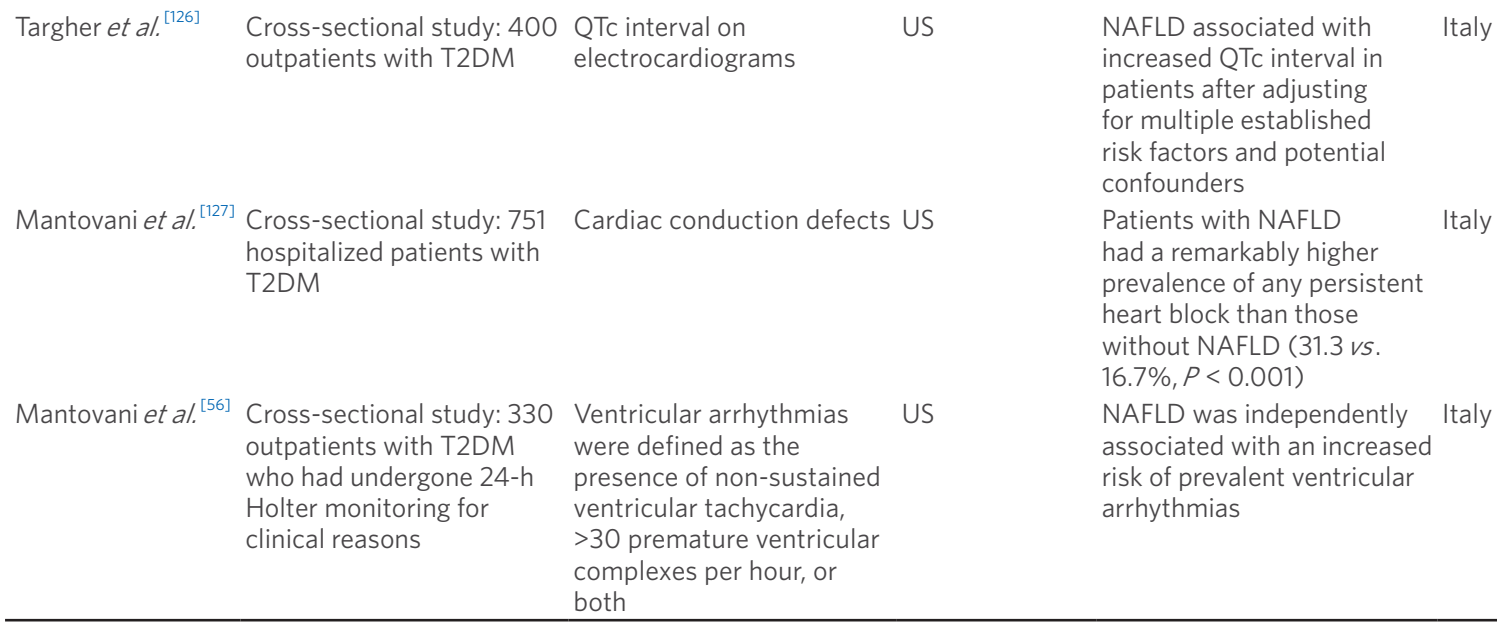

HCC: hepatocellular carcinoma; NAFLD: nonalcoholic fatty liver disease; T2DM: type 2 diabetes mellitus; US: ultrasound

independent risk factor for adverse outcomes in NAFLD patients with cirrhosis ${ }^{[119,120]}$. Specifically, T2DM is associated with important complications of cirrhosis, such as renal dysfunction, ascites, bacterial infections and hepatic encephalopathy ${ }^{[119,120]}$. Lastly, the management of patients with concurrent diabetes mellitus and liver disease has been also addressed ${ }^{[119,120]}$. Accumulating findings suggest a beneficial effect of metformin in patients with chronic liver diseases ${ }^{[119,120]}$. Insulin is often required in patients with advanced cirrhosis. However, the favorable impact of controlling diabetes mellitus in NAFLD patients with cirrhosis has not been clearly demonstrated yet ${ }^{[119,120]}$. Importantly, given that NAFLD has become one of the most important indications for liver transplantation, the management of multiple metabolic co-morbidities, including $\mathrm{T} 2 \mathrm{DM}$ and obesity, are strongly recommended in the pre- and peri-transplant period ${ }^{[128]}$.

An increased prevalence and incidence of hepatocellular carcinoma (HCC) has been observed in the last two decades worldwide. Although most cases of HCC are due to chronic infection with viral hepatitis, recent prospective studies have clearly documented that there is a close association between T2DM, NAFLD/NASH and risk of HCC ${ }^{[1]}$. For instance, in a USA population-based longitudinal study, enrolling approximately 4,400 cases of HCC with a median follow-up of 6 years, Sanyal et al. ${ }^{[121]}$ documented that the most common risk factor for HCC was NAFLD (59\%), followed by T2DM (36\%) and HCV chronic infection $(22 \%)$. Almost identical results were observed in a small cross-sectional study of 162 adults with $\mathrm{HCC}^{[122]}$. In that study, Ertle et al. ${ }^{[122]}$ found that NAFLD was the most frequent etiology for HCC. Importantly, studies have also suggested that the prevalence of HCC is higher in T2DM patients with NAFLD and that the coexistence of NAFLD and T2DM markedly increases the risk of developing HCC H.129-131] $_{\text {. }}$

The presence of T2DM and NAFLD seems to be also associated with intrahepatic cholangiocarcinoma (ICC). In a recent meta-analysis of 6 cohort and nested case-control studies, Petrick et al. ${ }^{[132]}$ reported that diabetes mellitus was associated with a 53\% increased risk of ICC (RR 1.53, 95\% confidence interval 1.31-1.78; $\mathrm{I}^{2}=67 \%$ ). In another study with a total of 6,093 cholangiocarcinoma cases (ICC: $n=4,695$; extrahepatic cholangiocarcinoma: $n=1,396$ ) and 60,906 age- and sex-matched controls, the patients with ICC and extrahepatic cholangiocarcinoma were more likely to have diabetes mellitus (adjusted odds ratio $1.22,95 \%$ confidence interval $1.07-1.39$ and $1.48,95 \%$ confidence interval $1.18-1.85$, respectively) than controls $^{[133]}$.

\section{NAFLD and risk of macro- and microvascular complications in patients with diabetes mellitus}

In the last decade, several observational studies documented that in patients with and without diabetes mellitus, NAFLD (as detected by imaging or liver biopsy) is associated with: (1) an increased risk of fatal 
and non-fatal cardiovascular events; (2) alterations in cardiac structure and function; and (3) an increased prevalence of microvascular complications [such as chronic kidney disease (CKD) and distal symmetric polyneuropathy $]^{[134]}$. Importantly, these associations were significant even after adjustment for many established cardiovascular risk factors and diabetes-related confounders ${ }^{[134]}$.

\section{Association between NAFLD and macrovascular complications}

It is now established that the principal cause of mortality in patients with NAFLD is cardiovascular disease (CVD), followed by extrahepatic cancers and liver-related complications ${ }^{[134]}$. In this regard, in a recent meta-analysis of 45 studies for a total of nearly 8 million individuals who were followed from 4 to 13 years, Younossi et al. ${ }^{[135]}$ documented that the pooled CVD-specific mortality rate among NAFLD patients (with or without diabetes mellitus) was approximately 4.8 per 1,000 person-years. Working with data from the National Vital Statistics System multiple-cause mortality data (2007-2016), Paik et al. ${ }^{[136]}$ further showed that CVD is one of the main causes of death among USA patients with NAFLD. In a 2016 meta-analysis of 16 observational studies, Targher et al. ${ }^{[137]}$ showed that patients with NAFLD had a higher risk of fatal and/or non-fatal CVD events when compared to patients with no NAFLD (random effects-odds ratio 1.64, $95 \%$ confidence interval 1.26-2.13) over a median period of nearly 7 years. In a 2020 nested cohort study of nearly 4,000 USA patients, who underwent coronary computed tomography angiography as part of the PROMISE (PROspective Multicenter Imaging Study for Evaluation of Chest Pain) study, Meyersohn et al. ${ }^{[138]}$ showed that hepatic steatosis (on computed tomography) was associated with major adverse cardiovascular events, even after controlling for established cardiovascular risk factors or extent of coronary artery disease (hazard ratio $1.69,95 \%$ confidence interval 1.16-2.48).

These findings can be broadly explained by the fact that NAFLD adversely affects cardiac structure and function, leading to an increased risk of cardiomyopathy (e.g., left ventricular diastolic dysfunction and hypertrophy), cardiac valvular calcification [e.g., aortic valve sclerosis (AVS) and mitral annulus calcification (MAC)], and cardiac arrhythmias (mainly atrial fibrillation) ${ }^{[134]}$.

Restricting the discussion to the observational studies conducted in patients with T2DM [Table 2], the Valpolicella Diabetes Heart Study in 2007 documented that T2DM patients with NAFLD (on ultrasound) had an increased prevalence of coronary, cerebrovascular and peripheral vascular diseases as compared with those with no NAFLD ${ }^{[123]}$. Interestingly, in a cross-sectional study enrolling 222 T2DM outpatients, Mantovani et al. ${ }^{[45]}$ documented that NAFLD (on ultrasound) was independently associated with increased risk of mild and/or moderate left ventricular diastolic dysfunction (evaluated by echocardiography). In another cross-sectional study of nearly 120 elderly T2DM patients with hypertension, Mantovani et al. ${ }^{[139]}$ reported that NAFLD (on ultrasound) was associated with left ventricular hypertrophy (as detected by echocardiography). In a cross-sectional study enrolling 19 adults with T2DM, 19 adults with NAFLD (on proton magnetic resonance spectroscopy $\left[{ }^{1} \mathrm{H}-\mathrm{MRS}\right]$ ) and 19 healthy controls, Cassidy et al. ${ }^{[124]}$ showed that alterations in cardiac structure (evaluated by cardiac magnetic resonance) were mainly evident in T2DM patients with NAFLD. Some studies using biopsy or Fibroscan ${ }^{\circ}$ also observed a graded relationship between functional and structural myocardial abnormalities and the severity of NAFLD in patients with and without $\mathrm{T} 2 \mathrm{DM}^{[134]}$.

Regarding the heart valve calcifications, studies have demonstrated an association between NAFLD and risk of AVS and MAC in patients with and without T2 $\mathrm{DM}^{[125,134]}$. For example, in an observational study enrolling 247 consecutive T2DM outpatients, Mantovani et al. ${ }^{[125]}$ reported that NAFLD (on ultrasound) was independently associated with cardiac calcifications in both the aortic and mitral valves. These findings are of clinical interest, as it is established that AVS and MAC are associated with all-cause and cardiovascular mortality in T2DM patients ${ }^{[140]}$. 
With regard to cardiac arrhythmias, many observational studies and some meta-analyses have reported that NAFLD (as detected by ultrasound or computed tomography) is associated with prevalent and incident atrial fibrillation in patients with and without $\mathrm{T} 2 \mathrm{DM}^{[134]}$. Atrial fibrillation is a frequent arrhythmia seen in clinical practice and it is closely related to cardiovascular morbidity and mortality ${ }^{[134]}$. In a meta-analysis of 5 observational studies enrolling approximately 240,000 middle-aged and elderly individuals, Mantovani et al. ${ }^{[141]}$ documented that NAFLD was associated with higher prevalence and incidence of AF. Other studies have documented that in T2DM patients, NAFLD (on ultrasound) was associated with an increased risk of prolonged QTc, ventricular arrhythmias or other conduction defects ${ }^{[56,126,127,134,142]}$.

Collectively, these data strongly support the assertion that, as also recommended by the European and American guidelines on the management of NAFLD ${ }^{[143,144]}$, a multidisciplinary approach to NAFLD patients is necessary, based on careful assessment of cardiometabolic risk factors.

\section{Increased risk of CKD in NAFLD patients with T2DM}

Recently, several studies and some meta-analyses have demonstrated that in T2DM patients, NAFLD, as detected by liver ultrasound or biopsy, is linked to an increased risk of prevalent and incident CKD, above and beyond established cardiometabolic risk factors ${ }^{[14]}$. For instance, regarding the association between NAFLD and prevalence of CKD, recently, in an observational study of 169 T2DM patients with NAFLD and 169 T2DM patients without NAFLD, Jia et al. ${ }^{[146]}$ reported that NAFLD (on ultrasound) was independently associated with an increased risk of prevalent CKD (defined as eGFR $<60 \mathrm{~mL} / \mathrm{min} / 1.73 \mathrm{~m}^{2}$ and/or albuminuria). Accumulating data now suggest that the association between NAFLD and risk of prevalent CKD may be even bidirectional ${ }^{[145]}$. For example, in an observational study enrolling approximately 2,000 Taiwanese patients with T2DM, Lee et al. ${ }^{[73]}$ confirmed an independent association between imaging-diagnosed NAFLD and CKD (adjusted odds ratio 1.59, 95\% confidence interval 1.12-2.25). Interestingly, when the authors performed a structural equation model analysis to test the effects of NAFLD on CKD and the potential role of CKD on NAFLD, they found the existence of a bidirectional relationship between NAFLD and $\mathrm{CKD}^{[73]}$.

Accumulating data also indicate that the risk of CKD may be higher in patients with advanced forms of NAFLD (mostly liver fibrosis) as compared to patients with simple steatosis ${ }^{[145]}$. In an observational crosssectional study enrolling nearly 400 Italian patients with T2DM, Lombardi et al. ${ }^{[71]}$ reported that CKD (defined by the presence of eGFR $\mathrm{CKD}_{\text {-EPI }}<60 \mathrm{~mL} / \mathrm{min} / 1.73 \mathrm{~m}^{2}$ and/or abnormal albuminuria) was present in $36 \%$ of NAFLD patients with liver fibrosis (as detected by Fibroscan ${ }^{\circ}$ ) as compared to $21 \%$ of NAFLD patients without liver fibrosis $(P<0.001)$. Recently, Mantovani et al. ${ }^{[65]}$ documented that, after adjusting for established risk factors and potential confounders, LSM was significantly associated with an approximately 3 -fold higher risk of prevalent CKD (adjusted odds ratio 3.28, 95\% confidence interval 1.22-8.90) in a sample of nearly $140 \mathrm{~T} 2 \mathrm{DM}$ outpatients. Interestingly, Yeung et al. ${ }^{[62]}$ in 2018 also reported that advanced fibrosis, as detected by Fibroscan ${ }^{\circ}$, but not liver steatosis on US, was independently associated with a higher risk of prevalent albuminuria in nearly 1,800 patients with T2DM (belonging to the Hong Kong Diabetes Registry). Additionally, in a cross-sectional study of 100 Indian patients with NAFLD (on US), Nampoothiri et al. ${ }^{[147]}$ reported that patients with impaired renal function (defined as eGFR Cockcoft-Gault $_{<}$ $80 \mathrm{~mL} / \mathrm{min} / 1.73 \mathrm{~m}^{2}$ and/or presence of proteinuria) had higher proportion of significant liver fibrosis and advanced fibrosis on Fibroscan ${ }^{\circledR}$, when compared to those with normal renal function. Importantly, in the multivariate analyses, the authors found that T2DM and advanced fibrosis were two independent predictors of impaired renal function in patients with NAFLD. In particular, advanced fibrosis had the best diagnostic accuracy and specificity in predicting impaired renal function in these patients (diagnostic accuracy: 81\%; sensitivity: $58 \%$; specificity: $90 \%)^{[147]}$.

Regarding the association between NAFLD and incidence of CKD, to date, there are still few data in patients with $\mathrm{T}_{2} \mathrm{DM}^{[148]}$. In 2008, the Valpolicella Heart Diabetes Study demonstrated that patients with 
T2DM and NAFLD had an increased risk of incident CKD (defined as CKD stage $\geq 3$ and/or overt proteinuria) as compared to those without NAFLD over a mean follow-up period of 6.5 years ${ }^{[149]}$. Recently, in a meta-analysis involving 9 cohort studies with a total of nearly 100,000 patients with and without T2DM, Mantovani et al. ${ }^{[150]}$ confirmed that NAFLD was independently associated with an increased risk of incident CKD. Interestingly, when the authors performed a subgroup analysis, they found that the risk of incident CKD in patients with NAFLD was greater in patients with T2DM (random effects hazard ratio 1.56, 95\% confidence interval 1.07-2.05) than in patients with no T2DM (random effects hazard ratio 1.35, 95\% confidence interval 1.16-1.54) ${ }^{[150]}$.

Accumulating data also suggest that NAFLD patients with CKD tend to have a worse prognosis and an increased overall mortality as well, when compared to those with NAFLD but without $\mathrm{CKD}^{[148]}$. For instance, in a cohort study enrolling 11,695 patients, Paik et al. ${ }^{[151]}$ documented that the presence of both CKD and NAFLD was associated with an increased risk for overall mortality (hazard ratio 2.34, 95\% confidence interval 1.91-2.87). Interestingly, in that study, the severity of CKD was even associated with higher risk of mortality in patients with NAFLD ${ }^{[151]}$. Specifically, the presence of NAFLD with advanced CKD stages (from stage $3 \mathrm{~B}$ to stage 5 ) was associated with a nearly 5 -fold (hazard ratio $4.80,95 \%$ confidence interval 2.40-9.71) increased risk of death when compared to absence of CKD, whereas the presence of NAFLD with intermediate CKD stages (from stage 2 to stage $3 \mathrm{~A}$ ) was associated with a 2.3-fold (95\% confidence interval 1.70-3.15) increased risk of death ${ }^{[151]}$. Although further studies are needed, it is possible that the difference in overall mortality observed by Paik et al.$^{[151]}$ might be related to the presence of specific metabolic features, including T2DM. Önnerhag et al. ${ }^{[152]}$ corroborated this hypothesis in an observational study involving 120 patients with biopsy-diagnosed NAFLD.

Recently, some observational studies that enrolled patients with and without T2DM have documented that PNPLA3 rs738409 (I148M protein variant), which is the most important variant associated with NAFLD and its severe forms, is independently associated with an increased risk of $\mathrm{CKD}^{[145,148]}$. For instance, in a recent study of 157 Italian patients with T2DM, who underwent liver ultrasound and kidney function assessment, Mantovani et al ${ }^{[153]}$ reported that the association of I148M homozygosity with higher risk of CKD was independent of liver disease severity and other confounders. Interestingly, in that study, the authors also found that PNPLA3 mRNA expression was greatest in liver and renal cortex, especially in podocytes, thereby suggesting that PNPLA3 I148M variant might exert adverse effects on the kidney ${ }^{[153]}$.

\section{Association between NAFLD and distal symmetric polyneuropathy in patients with diabetes mellitus}

Several observational studies, although not all ${ }^{[154,155]}$, have documented a significant association between NAFLD and prevalent distal symmetric polyneuropathy in patients with $\mathrm{T} 2 \mathrm{DM}^{[22,39,71]}$. This association persisted even after adjustment for many cardiometabolic risk factors and other potential confounders. Interestingly, in a recent cross-sectional study involving approximately 400 outpatients with T2DM (mean age 68 years, 52\% male) attending 5 Italian diabetes centers, who underwent liver ultrasonography, FibroScan ${ }^{\odot}$ and evaluation of microvascular diabetic complications, Lombardi et al. ${ }^{[71]}$ documented that significant fibrosis (i.e., $\mathrm{LSM} \geq 7.0 / 6.2 \mathrm{kPa}$ with $\mathrm{M} / \mathrm{XL}$ probes) was independently associated with increased prevalence of microvascular diabetic complications, including distal symmetric polyneuropathy ( $3 \%$ in patients with $\mathrm{LSM}<7.0 / 6.2 \mathrm{kPa}$ vs. $14 \%$ in patients with $\mathrm{LSM} \geq 7.0 / 6.2 \mathrm{kPa}$ ). Contrariwise, in a retrospective study of 927 Asian patients with T2DM, Kim et al. ${ }^{[155]}$ did not observe a significant difference in the prevalence of diabetic peripheral neuropathy among patients with and without NAFLD.

Collectively, these data suggest that diabetic patients with NAFLD should be evaluated for the presence of distal symmetric polyneuropathy, along with other hepatic and extrahepatic complications. In addition, the issue of whether the increased risk of microvascular complications in diabetic patients with NAFLD is 
restricted to patients with more severe NAFLD or applies to all patients with NAFLD is relevant given the disease burden of NAFLD. However, additional studies are needed to establish if NAFLD can increase the risk of developing distal symmetric polyneuropathy and to elucidate if improvement in NAFLD is able to prevent the development and progression of distal symmetric polyneuropathy in patients with diabetes.

\section{Putative mechanisms linking NAFLD to vascular complications in patients with diabetes mellitus}

The detailed description of the putative mechanisms linking NALFD to vascular complications in patients with diabetes mellitus is beyond the purpose of this narrative review. Therefore, we refer the reader to other reviews for this topic ${ }^{[1,2,134,142,156]}$.

When common diseases coexist and share common risk factors, it might be difficult to separate pivotal relationships and understand the role of potential confounders. Indeed, T2DM or MetS are examples of confounding diseases linking NAFLD to cardiovascular complications.

However, there are many potential underlying mechanisms that can link NAFLD to the development and progression of vascular complications ${ }^{[134]}$. As several studies have clearly demonstrated in the last decade, NAFLD (mainly in its more severe histological forms) can worsen hepatic and systemic insulin resistance ${ }^{[156]}$. Insulin resistance is linked to an excessive fat accumulation in ectopic tissues, including the liver, as well as with increased circulating free fatty acids ${ }^{[156]}$. All these factors can strongly promote endoplasmic reticulum stress and inflammation ${ }^{[156]}$. In addition, they aggravate and maintain the insulin resistant state, thereby leading to a vicious $\mathrm{cycle}^{[156]}$. In fact, inhibition of insulin signaling pathways associated with NAFLD can occur by various mechanisms, including inflammatory, many kinase proteins and several lipid-derived by-products ${ }^{[156]}$. NAFLD and its more severe histological forms can also contribute to the release into the bloodstream of several proinflammatory, profibrogenic and vasoactive mediators (such as C-reactive protein, tumor necrosis factor alpha, interleukin-6, transforming growth factorbeta, factor VIII, plasminogen activator inhibitor-1 and endothelin-1). All these mediators can promote important cardiac and arrhythmic complications ${ }^{[134]}$. Hence, it is possible that the reduction of chronic inflammation in NAFLD patients might be a potential intervention to reduce the risk of cardiac disease and arrhythmias ${ }^{[134]}$. Accumulating experimental and clinical data also indicate that NAFLD may contribute to the activation of multiple pathways implicated in the pathophysiology of $\mathrm{CKD}^{[1,2,134,142]}$. Impaired activation of the renin-angiotensin system (RAS) may indeed contribute to the renovascular injury by inflammation and coagulation pathways ${ }^{[1,2,134,142]}$. Atherogenic dyslipidemia, insulin resistance, oxidative stress and pro-inflammatory factors can contribute to renal damage ${ }^{[1,2,134,142]}$. However, in spite of the large body of evidence linking NAFLD to cardiac, arrhythmic and renal complications, it has not been conclusively established if a cause-effect relationship exists ${ }^{[134]}$.

Not only are many traditional risk factors combined between NAFLD, micro and macrovascular disease, $\mathrm{CKD}$ and T2DM/MetS, but novel risk factors are also emerging in each of these conditions. These novel risk factors include perturbation of the intestinal microbiota (dysbiosis) with associated inflammation, intestinal dysfunction and platelet activation.

Recently, the role of dysbiosis in NAFLD and in the development of its complications has gained scientific interest ${ }^{[134]}$. Dysbiosis is associated with increased production of lipopolysaccharide from gramnegative bacteria, which can damage the intestinal barrier and, consequently, can increase permeability and contribute to the release of endotoxins into the systemic circulation, thereby determining a chronic inflammation and oxidative stress, mainly due to the release of pro-inflammatory cytokines ${ }^{[134,157]}$. 
Altered production of short-chain fatty acids, such as acetate, propionate and butyrate, can influence hepatic gluconeogenesis and liponeogenesis ${ }^{[158]}$. Short-term probiotic treatments should have a beneficial effect on insulin resistance by increasing butyrate production $^{[158]}$.

Another consequence of dysbiosis is an increase in the uremic toxins that are associated with atherosclerosis and hypertension. There is a demonstrated relationship between trimethylamine oxide (TMAO) and atherosclerosis ${ }^{[159]}$. Circulating levels of TMAO, an early biomarker of adipose dysfunction, are high in obese NAFLD patients ${ }^{[159]}$. TMAO is produced from the oxidation of trimethylamine in the liver, which is derived from bacteria-dependent metabolism of dietary choline ${ }^{[159]}$. TMAO leads to atherosclerosis acting on reverse cholesterol transport, inducing platelet aggregation, the formation of foam cells and the increased expression of scavenger receptors ${ }^{[159]}$.

Cardiovascular tissue cells, such as endothelial cells, vascular smooth cells and cardiac cells, express bile acid receptors ${ }^{[160]}$. Gut microbiota influence the production of secondary bile acids, such as deoxycholic acid, ursodeoxycholic acid and lithocholic acid ${ }^{[160]}$. The alteration of bile acid metabolism seems to be associated with an increased risk of CVD, because of increased LDL cholesterol levels, vasomotor tone and blood pressure ${ }^{[160]}$.

Several experimental studies also suggest that mitochondrial dysfunction may be closely associated with insulin resistance and atherosclerosis ${ }^{[161]}$, thereby indicating a potential mechanistic link between mitochondrial dysfunction, T2DM, NAFLD and CVD ${ }^{[134]}$.

Recently, Malehmir et al. ${ }^{[162]}$ showed that platelet number, platelet activation and platelet aggregation are increased in NASH, but not in simple steatosis, pointing to novel mechanisms that should be studied.

We suggest that future prospective and interventional studies be carried out in well-characterised cohorts of patients that can clarify mechanisms linking NALFD to vascular complications.

\section{CONCLUSION}

The concept that NAFLD is a benign condition has changed over the last decades. At present, NAFLD is the most common chronic liver disease observed in clinical practice, especially in patients with T2DM and those with obesity, thereby becoming a relevant health care problem worldwide ${ }^{[1,86,135]}$. In fact, NAFLD is a leading cause of liver-related and cardiovascular mortality and morbidity ${ }^{[1]}$. Convincing evidence clearly shows that NAFLD is strongly linked to clinical and subclinical alterations in cardiac structure and function, independent of the coexistence of established cardiovascular risk factors and metabolic syndrome ${ }^{[134]}$. These findings may partly explain the increased risk of cardiovascular death found in T2DM patients with NAFLD. Given the available data and as suggested by European and American clinical practice guidelines ${ }^{[143,144]}$, a careful assessment of cardiometabolic risk factors and regular monitoring of liver and cardiovascular complications is mandatory in patients with NAFLD, especially if they are obese or have T2DM. Some authors suggest repeating the assessments every 1 or 2 years, based on the CVD risk factors ${ }^{[4]}$. The clinical and laboratory data that should be obtained, along with sex and age, are as follows: body weight, height, body mass index, waist circumference, cigarette smoking, alcohol consumption, blood pressure, total cholesterol, triglycerides, HDL-cholesterol, LDL-cholesterol, fasting plasma glucose, hemoglobin A1c (HbA1c), estimated glomerular filtration rate (or serum creatinine), albuminuria, 75 -g oral glucose tolerance test (in patients with impaired fasting glycaemia and/or obesity), CVD risk estimation (by using risk calculators), and carotid artery ultrasonography ${ }^{[4]}$. In addition, seeing that the prevalence of NAFLD and significant or advanced liver fibrosis is relatively high in T2DM patients (most of whom have normal serum levels of liver enzymes) ${ }^{[1]}$, FibroScan ${ }^{\circledR}$ may be useful not only for assessing the severity of liver fibrosis, which is the strongest predictor of long-term adverse clinical outcomes in 
NAFLD, but also for identifying those patients at higher risk of having CKD or other chronic vascular complications $^{[1,65]}$. Finally, despite the large body of evidence on NAFLD in T2DM patients, there are still important open issues that need to be timely resolved:

(1) Is MAFLD definition more useful in clinical practice when compared to NAFLD definition?

(2) Which are the appropriate screening/surveillance measures for NAFLD in individuals with T2DM?

(3) Which is the appropriate non-invasive diagnostic strategy for NASH and advanced fibrosis in T2DM patients with NAFLD?

(4) Is NAFLD a risk factor or only an independent predictor of non-hepatic complications in patients with $\mathrm{T} 2 \mathrm{DM}$, including cardiovascular disease?

(5) What is the role of genetic factors regarding the development of advanced forms of NAFLD in patients with T2DM?

\section{DECLARATIONS}

\section{Authors' contributions}

Made substantial contributions to conception and design of the study and performed data analysis and interpretation, performed data acquisition, as well as provided administrative, technical and material support: Mantovani A, Beatrice G, Sputia R, Dalbeni A

\section{Availability of data and materials}

Not applicable.

\section{Financial support and sponsorship}

None.

\section{Conflicts of interest}

All authors declared that there are no conflicts of interest.

\section{Ethical approval and consent to participate}

Not applicable.

\section{Consent for publication}

Not applicable.

\section{Copyright}

(c) The Author(s) 2020.

\section{REFERENCES}

1. Mantovani A, Scorletti E, Mosca A, Alisi A, Byrne CD, Targher G. Complications, morbidity and mortality of nonalcoholic fatty liver disease. Metabolism 2020;111S:154170.

2. Targher G, Lonardo A, Byrne CD. Nonalcoholic fatty liver disease and chronic vascular complications of diabetes mellitus. Nat Rev Endocrinol 2018;14:99-114.

3. Lonardo A, Mantovani A, Lugari S, Targher G. Epidemiology and pathophysiology of the association between NAFLD and metabolically healthy or metabolically unhealthy obesity. Ann Hepatol 2020;19:359-66.

4. Lonardo A, Nascimbeni F, Mantovani A, Targher G. Hypertension, diabetes, atherosclerosis and NASH: Cause or consequence? $J$ Hepatol 2018;68:335-52.

5. Ortiz-Lopez C, Lomonaco R, Orsak B, et al. Prevalence of prediabetes and diabetes and metabolic profile of patients with nonalcoholic fatty liver disease (NAFLD). Diabetes Care 2012;35:873-8.

6. Williams KH, Shackel NA, Gorrell MD, McLennan SV, Twigg SM. Diabetes and nonalcoholic Fatty liver disease: a pathogenic duo. Endocr Rev 2013;34:84-129.

7. Targher G, Marchesini G, Byrne CD. Risk of type 2 diabetes in patients with non-alcoholic fatty liver disease: Causal association or epiphenomenon? Diabetes Metab 2016;42:142-56. 
8. Adams LA, Anstee QM, Tilg H, Targher G. Non-alcoholic fatty liver disease and its relationship with cardiovascular disease and other extrahepatic diseases. Gut 2017;66:1138-53.

9. Eslam M, Sanyal AJ, George J; International Consensus Panel. MAFLD: A Consensus-Driven Proposed Nomenclature for Metabolic Associated Fatty Liver Disease. Gastroenterology 2020;158:1999-2014.e1.

10. Tilg H, Effenberger M. From NAFLD to MAFLD: when pathophysiology succeeds. Nat Rev Gastroenterol Hepatol 2020;17:387-8.

11. Fouad Y, Waked I, Bollipo S, Gomaa A, Ajlouni Y, Attia D. What's in a name? Renaming 'NAFLD' to 'MAFLD'. Liver Int 2020;40:125461.

12. Portillo-Sanchez P, Bril F, Maximos M, et al. High Prevalence of Nonalcoholic Fatty Liver Disease in Patients With Type 2 Diabetes Mellitus and Normal Plasma Aminotransferase Levels. J Clin Endocrinol Metab 2015;100:2231-8.

13. Kwok R, Choi KC, Wong GL, et al. Screening diabetic patients for non-alcoholic fatty liver disease with controlled attenuation parameter and liver stiffness measurements: a prospective cohort study. Gut 2016;65:1359-68.

14. Arab JP, Barrera F, Gallego C, et al. High prevalence of undiagnosed liver cirrhosis and advanced fibrosis in type 2 diabetic patients. Ann Hepatol 2016;15:721-8.

15. Jung $\mathrm{CH}$, Lee $\mathrm{B}$, Choi $\mathrm{DH}$, et al. Association of grade of non-alcoholic fatty liver disease and glycated albumin to glycated hemoglobin ratio in patients with type 2 diabetes mellitus. Diabetes Res Clin Pract 2017;125:53-61.

16. Masarone M, Rosato V, Aglitti A, et al. Liver biopsy in type 2 diabetes mellitus: Steatohepatitis represents the sole feature of liver damage. PLoS One 2017;12:e178473.

17. Petit JM, Pedro L, Guiu B, et al. Type 1 diabetes is not associated with an increased prevalence of hepatic steatosis. Diabet Med 2015;32:1648-51.

18. Wilman HR, Kelly M, Garratt S, et al. Characterisation of liver fat in the UK Biobank cohort. PLoS One 2017;12:e172921.

19. Doycheva I, Cui J, Nguyen P, et al. Non-invasive screening of diabetics in primary care for NAFLD and advanced fibrosis by MRI and MRE. Aliment Pharmacol Ther 2016;43:83-95.

20. Ding X, Xu Y, Wang Y, et al. Nonalcoholic fatty liver disease and associated metabolic risks of hypertension in type 2 diabetes: a crosssectional community-based study. Int J Endocrinol 2017;2017:5262560.

21. Al Rifai M, Silverman MG, Nasir K, et al. The association of nonalcoholic fatty liver disease, obesity, and metabolic syndrome, with systemic inflammation and subclinical atherosclerosis: the Multi-Ethnic Study of Atherosclerosis (MESA). Atherosclerosis 2015;239:62933.

22. Williams KH, Burns K, Constantino M, et al. An association of large-fibre peripheral nerve dysfunction with non-invasive measures of liver fibrosis secondary to non-alcoholic fatty liver disease in diabetes. J Diabetes Complications 2015;29:1240-7.

23. Cusi K, Sanyal AJ, Zhang S, et al. Non-alcoholic fatty liver disease (NAFLD) prevalence and its metabolic associations in patients with type 1 diabetes and type 2 diabetes. Diabetes Obes Metab 2017;19:1630-4.

24. Guo K, Zhang L, Lu J, et al. Non-alcoholic fatty liver disease is associated with late but not early atherosclerotic lesions in Chinese inpatients with type 2 diabetes. J Diabetes Complications 2017;31:80-5.

25. Herath HMM, Kodikara I, Weerarathna TP, Liyanage G. Prevalence and associations of non-alcoholic fatty liver disease (NAFLD) in Sri Lankan patients with type 2 diabetes: A single center study. Diabetes Metab Syndr 2019;13:246-50.

26. Sberna AL, Bouillet B, Rouland A, et al. European Association for the Study of the Liver (EASL), European Association for the Study of Diabetes (EASD) and European Association for the Study of Obesity (EASO) clinical practice recommendations for the management of non-alcoholic fatty liver disease: evaluation of their application in people with Type 2 diabetes. Diabet Med 2018;35:368-75.

27. Krishan S. Correlation between non-alcoholic fatty liver disease (NAFLD) and dyslipidemia in type 2 diabetes. Diabetes Metab Syndr 2016;10:S77-81.

28. Su X, Xu J, Zheng C. The relationship between non-alcoholic fatty liver and skeletal muscle mass to visceral fat area ratio in women with type 2 diabetes. BMC Endocr Disord 2019;19:76.

29. Vanjiappan S, Hamide A, Ananthakrishnan R, Periyasamy SG, Mehalingam V. Nonalcoholic fatty liver disease in patients with type 2 diabetes mellitus and its association with cardiovascular disease. Diabetes Metab Syndr 2018;12:479-82.

30. He X, Shen Y, Ma X, et al. The association of serum FGF23 and non-alcoholic fatty liver disease is independent of vitamin D in type 2 diabetes patients. Clin Exp Pharmacol Physiol 2018;45:668-74.

31. Kabir MA, Uddin MZ, Siddiqui NI, et al. Prevalence of non-alcoholic fatty liver disease and its biochemical predictors in patients with type-2 diabetes mellitus. Mymensingh Med J 2018;27:237-44.

32. Lai LL, Wan Yusoff WNI, Vethakkan SR, Nik Mustapha NR, Mahadeva S, Chan WK. Screening for non-alcoholic fatty liver disease in patients with type 2 diabetes mellitus using transient elastography. J Gastroenterol Hepatol 2019;34:1396-403.

33. Hashimoto Y, Osaka T, Fukuda T, Tanaka M, Yamazaki M, Fukui M. The relationship between hepatic steatosis and skeletal muscle mass index in men with type 2 diabetes. Endocr J 2016;63:877-84.

34. Zou Y, Li X, Wang C, et al. Association between non-alcoholic fatty liver disease and peripheral artery disease in patients with type 2 diabetes. Intern Med J 2017;47:1147-53.

35. Afolabi BI, Ibitoye BO, Ikem RT, Omisore AD, Idowu BM, Soyoye DO. The relationship between glycaemic control and non-alcoholic fatty liver disease in nigerian type 2 diabetic patients. $J$ Natl Med Assoc 2018;110:256-64.

36. Moh Moh MA, Jung CH, Lee B, et al. Association of glucagon-to-insulin ratio and nonalcoholic fatty liver disease in patients with type 2 diabetes mellitus. Diab Vasc Dis Res 2019;16:186-95.

37. Cosma A, Cecchet D, Gaiani S, et al. Clinical and biochemical determinants of the extent of liver steatosis in type 2 diabetes mellitus. Eur J Gastroenterol Hepatol 2015;27:1386-91. 
38. Almobarak AO, Barakat S, Suliman EA, et al. Prevalence of and predictive factors for nonalcoholic fatty liver disease in Sudanese individuals with type 2 diabetes: Is metabolic syndrome the culprit? Arab J Gastroenterol 2015;16:54-8.

39. Yan LH, Mu B, Guan Y, et al. Assessment of the relationship between non-alcoholic fatty liver disease and diabetic complications. $J$ Diabetes Investig 2016;7:889-94.

40. Alsabaani AA, Mahfouz AA, Awadalla NJ, Musa MJ, Al Humayed SM. Non-Alcoholic fatty liver disease among type-2 diabetes mellitus patients in abha city, south western saudi arabia. Int J Environ Res Public Health 2018;15:2521.

41. Gutierrez-Buey G, Núñez-Córdoba JM, Llavero-Valero M, Gargallo J, Salvador J, Escalada J. Is HOMA-IR a potential screening test for non-alcoholic fatty liver disease in adults with type 2 diabetes? Eur J Intern Med 2017;41:74-8.

42. Zawdie B, Tadesse S, Wolide AD, Nigatu TA, Bobasa EM. Non-alcoholic fatty liver disease and associated factors among type 2 diabetic patients in southwest ethiopia. Ethiop J Health Sci 2018;28:19-30.

43. Dvorak K, Hainer R, Petrtyl J, et al. The prevalence of nonalcoholic liver steatosis in patients with type 2 diabetes mellitus in the Czech Republic. Biomed Pap Med Fac Univ Palacky Olomouc Czech Repub 2015;159:442-8.

44. Hua X, Li M, Pan F, Xiao Y, Cui W, Hu Y. Non-alcoholic fatty liver disease is an influencing factor for the association of SHBG with metabolic syndrome in diabetes patients. Sci Rep 2017;7:14532.

45. Mantovani A, Pernigo M, Bergamini C, et al. Nonalcoholic fatty liver disease is independently associated with early left ventricular diastolic dysfunction in patients with type 2 diabetes. PLoS One 2015;10:e135329.

46. Olusanya TO, Lesi OA, Adeyomoye AA, Fasanmade OA. Non alcoholic fatty liver disease in a Nigerian population with type II diabetes mellitus. Pan Afr Med J 2016;24:20.

47. Chang W, Wang Y, Sun L, Yu D, Li Y, Li G. Evaluation of left atrial function in type 2 diabetes mellitus patients with nonalcoholic fatty liver disease by two-dimensional speckle tracking echocardiography. Echocardiography 2019;36:1290-7.

48. Zhao CC, Wang AP, Li LX, et al. Urine uric acid excretion is associated with nonalcoholic fatty liver disease in patients with type 2 diabetes. J Diabetes Complications 2016;30:1074-80.

49. Zhang J, Zhang B, Cheng Y, Xu J. Low serum CTRP3 levels are associated with nonalcoholic fatty liver disease in patients with type 2 diabetes mellitus. Cytokine 2018;106:131-5.

50. Johansen ML, Schou M, Rasmussen J, et al. Low N-terminal pro-brain natriuretic peptide levels are associated with non-alcoholic fatty liver disease in patients with type 2 diabetes. Diabetes Metab 2019;45:429-35.

51. Fan N, Zhang L, Xia Z, Peng L, Wang Y, Peng Y. Sex-specific association between serum uric acid and nonalcoholic fatty liver disease in type 2 diabetic patients. J Diabetes Res 2016;2016:3805372.

52. García Díaz E, Guagnozzi D, Gutiérrez V, et al. Effect of incretin therapies compared to pioglitazone and gliclazide in non-alcoholic fatty liver disease in diabetic patients not controlled on metformin alone: An observational, pilot study. Endocrinol Nutr 2016;63:194-201.

53. Demir M, Deyneli O, Y1lmaz Y. Screening for hepatic fibrosis and steatosis in Turkish patients with type 2 diabetes mellitus: A transient elastography study. Turk J Gastroenterol 2019;30:266-70.

54. Petit JM, Masson D, Guiu B, et al. GCKR polymorphism influences liver fat content in patients with type 2 diabetes. Acta Diabetol 2016;53:237-42.

55. Zhao H, Song X, Li Z, Wang X. Risk factors associated with nonalcohol fatty liver disease and fibrosis among patients with type 2 diabetes mellitus. Medicine (Baltimore) 2018;97:e12356.

56. Mantovani A, Rigamonti A, Bonapace S, et al. Nonalcoholic fatty liver disease is associated with ventricular arrhythmias in patients with type 2 diabetes referred for clinically indicated 24-hour holter monitoring. Diabetes Care 2016;39:1416-23.

57. Barchetta I, Cimini FA, De Gioannis R, et al. Procollagen-III peptide identifies adipose tissue-associated inflammation in type 2 diabetes with or without nonalcoholic liver disease. Diabetes Metab Res Rev 2018;34:e2998.

58. Choe EY, Lee YH, Choi YJ, et al. Waist-to-calf circumstance ratio is an independent predictor of hepatic steatosis and fibrosis in patients with type 2 diabetes. J Gastroenterol Hepatol 2018;33:1082-91.

59. Silaghi CA, Silaghi H, Crăciun AE, et al. Age, abdominal obesity, and glycated hemoglobin are associated with carotid atherosclerosis in type 2 diabetes patients with nonalcoholic fatty liver disease. Med Ultrason 2015;17:300-7.

60. Lee H, Kim G, Choi YJ, et al. Association between non-alcoholic steatohepatitis and left ventricular diastolic dysfunction in type 2 diabetes mellitus. Diabetes Metab J 2020;44:267-76.

61. Seo DH, Lee YH, Park SW, et al. Sarcopenia is associated with non-alcoholic fatty liver disease in men with type 2 diabetes. Diabetes Metab 2020;46:362-9.

62. Yeung MW, Wong GL, Choi KC, et al. Advanced liver fibrosis but not steatosis is independently associated with albuminuria in Chinese patients with type 2 diabetes. $J$ Hepatol 2017:147-56.

63. Bellan M, Colletta C, Barbaglia MN, et al. Severity of nonalcoholic fatty liver disease in type 2 diabetes mellitus: relationship between nongenetic factors and PNPLA3/HSD17B13 polymorphisms. Diabetes Metab J 2019;43:700-10.

64. Tuong TTK, Tran DK, Phu PQT, Hong TND, Dinh TC, Chu DT. Non-alcoholic fatty liver disease in patients with type 2 diabetes: evaluation of hepatic fibrosis and steatosis using fibroscan. Diagnostics (Basel) 2020;10:159.

65. Mantovani A, Turino T, Lando MG, et al. Screening for non-alcoholic fatty liver disease using liver stiffness measurement and its association with chronic kidney disease and cardiovascular complications in patients with type 2 diabetes. Diabetes Metab 2020;46:296303.

66. Choi DH, Jung CH, Mok JO, Kim CH, Kang SK, Kim BY. Nonalcoholic fatty liver disease and abdominal fat accumulation according to vitamin d status in patients with type 2 diabetes. J Obes Metab Syndr 2018;27:53-60.

67. Heidari Z, Gharebaghi A. Prevalence of non alcoholic fatty liver disease and its association with diabetic nephropathy in patients with 
type 2 diabetes mellitus. J Clin Diagn Res 2017;11:OC04-7.

68. Mandal A, Bhattarai B, Kafle P, et al. Elevated liver enzymes in patients with type 2 diabetes mellitus and non-alcoholic fatty liver disease. Cureus 2018;10:e3626.

69. Motta BM, Grander C, Gögele M, et al. Microbiota, type 2 diabetes and non-alcoholic fatty liver disease: protocol of an observational study. J Transl Med 2019;17:408.

70. Sporea I, Mare R, Popescu A, et al. Screening for liver fibrosis and steatosis in a large cohort of patients with type 2 diabetes using vibration controlled transient elastography and controlled attenuation parameter in a single-center real-life experience. J Clin Med 2020;9:1032.

71. Lombardi R, Airaghi L, Targher G, et al. Liver fibrosis by FibroScan ${ }^{\circledR}$ independently of established cardiovascular risk parameters associates with macrovascular and microvascular complications in patients with type 2 diabetes. Liver Int 2020;40:347-54.

72. Hamid S, Subhan Butt A, Sharif F, et al. Nonalcoholic fatty liver diseases among recently diagnosed patients with diabetes mellitus and risk factors. Euroasian J Hepatogastroenterol 2019;9:9-13.

73. Lee YJ, Wang CP, Hung WC, et al. Common and unique factors and the bidirectional relationship between chronic kidney disease and nonalcoholic fatty liver in type 2 diabetes patients. Diabetes Metab Syndr Obes 2020;13:1203-14.

74. El-Ashmawy HM, Ahmed AM. Serum fetuin-B level is an independent marker for nonalcoholic fatty liver disease in patients with type 2 diabetes. Eur J Gastroenterol Hepatol 2019;31:859-64.

75. Mangla N, Ajmera VH, Caussy C, et al. Liver stiffness severity is associated with increased cardiovascular risk in patients with type 2 diabetes. Clin Gastroenterol Hepatol 2020;18:744-6.e1.

76. Byrne CD, Patel J, Scorletti E, Targher G. Tests for diagnosing and monitoring non-alcoholic fatty liver disease in adults. $B M J$ 2018;362:k2734.

77. Wang CC, Tseng TC, Hsieh TC, et al. Severity of fatty liver on ultrasound correlates with metabolic and cardiovascular risk. Kaohsiung $J$ Med Sci 2012;28:151-60.

78. Chen K, Sng WK, Quah JH, et al. Clinical spectrum of non-alcoholic fatty liver disease in patients with diabetes mellitus. PLoS One 2020;15:e0236977.

79. Gerber L, Otgonsuren M, Mishra A, et al. Non-alcoholic fatty liver disease (NAFLD) is associated with low level of physical activity: a population-based study. Aliment Pharmacol Ther 2012;36:772-81.

80. Zelber-Sagi S, Salomone F, Mlynarsky L. The mediterranean dietary pattern as the diet of choice for non-alcoholic fatty liver disease; Evidence and plausible mechanisms. Liver Int 2017;37:936-49.

81. Eslam M, Valenti L, Romeo S. Genetics and epigenetics of NAFLD and NASH: clinical impact. J Hepatol 2018;68:268-79.

82. Bazick J, Donithan M, Neuschwander-Tetri BA, et al. Clinical model for NASH and advanced fibrosis in adult patients with diabetes and NAFLD: guidelines for referral in NAFLD. Diabetes Care 2015;38:1347-55.

83. McPherson S, Hardy T, Henderson E, Burt AD, Day CP, Anstee QM. Evidence of NAFLD progression from steatosis to fibrosingsteatohepatitis using paired biopsies: implications for prognosis and clinical management. J Hepatol 2015;62:1148-55.

84. Loomba R, Abraham M, Unalp A, et al; Nonalcoholic Steatohepatitis Clinical Research Network. Association between diabetes, family history of diabetes, and risk of nonalcoholic steatohepatitis and fibrosis. Hepatology 2012;56:943-51.

85. Puchakayala BK, Verma S, Kanwar P, Hart J, Sanivarapu RR, Mohanty SR. Histopathological differences utilizing the nonalcoholic fatty liver disease activity score criteria in diabetic (type 2 diabetes mellitus) and non-diabetic patients with nonalcoholic fatty liver disease. World J Hepatol 2015;7:2610-8.

86. Younossi ZM, Golabi P, de Avila L, et al. The global epidemiology of NAFLD and NASH in patients with type 2 diabetes: A systematic review and meta-analysis. J Hepatol 2019;71:793-801.

87. Targher G, Byrne CD. Clinical review: nonalcoholic fatty liver disease: a novel cardiometabolic risk factor for type 2 diabetes and its complications. J Clin Endocrinol Metab 2013;98:483-95.

88. Okamoto M, Takeda Y, Yoda Y, Kobayashi K, Fujino MA, Yamagata Z. The association of fatty liver and diabetes risk. J Epidemiol 2003;13:15-21.

89. Shibata M, Kihara Y, Taguchi M, Tashiro M, Otsuki M. Nonalcoholic fatty liver disease is a risk factor for type 2 diabetes in middle-aged Japanese men. Diabetes Care 2007;30:2940-4.

90. Kim CH, Park JY, Lee KU, Kim JH, Kim HK. Fatty liver is an independent risk factor for the development of Type 2 diabetes in Korean adults. Diabet Med 2008;25:476-81.

91. Bae JC, Rhee EJ, Lee WY, et al. Combined effect of nonalcoholic fatty liver disease and impaired fasting glucose on the development of type 2 diabetes: a 4-year retrospective longitudinal study. Diabetes Care 2011;34:727-9.

92. Park SK, Seo MH, Shin HC, Ryoo JH. Clinical availability of nonalcoholic fatty liver disease as an early predictor of type 2 diabetes mellitus in Korean men: 5-year prospective cohort study. Hepatology 2013;57:1378-83.

93. Sung KC, Jeong WS, Wild SH, Byrne CD. Combined influence of insulin resistance, overweight/obesity, and fatty liver as risk factors for type 2 diabetes. Diabetes Care 2012;35:717-22.

94. Kasturiratne A, Weerasinghe S, Dassanayake AS, et al. Influence of non-alcoholic fatty liver disease on the development of diabetes mellitus. J Gastroenterol Hepatol 2013;28:142-7.

95. Chang Y, Jung HS, Yun KE, Cho J, Cho YK, Ryu S. Cohort study of non-alcoholic fatty liver disease, NAFLD fibrosis score, and the risk of incident diabetes in a Korean population. Am J Gastroenterol 2013;108:1861-8.

96. Choi JH, Rhee EJ, Bae JC, et al. Increased risk of type 2 diabetes in subjects with both elevated liver enzymes and ultrasonographically diagnosed nonalcoholic fatty liver disease: a 4-year longitudinal study. Arch Med Res 2013;44:115-20. 
97. Yamazaki H, Tsuboya T, Tsuji K, Dohke M, Maguchi H. Independent association between improvement of nonalcoholic fatty liver disease and reduced incidence of type 2 diabetes. Diabetes Care 2015;38:1673-9.

98. Ming J, Xu S, Gao B, et al. Non-alcoholic fatty liver disease predicts type 2 diabetes mellitus, but not prediabetes, in Xi'an, China: a fiveyear cohort study. Liver Int 2015;35:2401-7.

99. Li WD, Fu KF, Li GM, et al. Comparison of effects of obesity and non-alcoholic fatty liver disease on incidence of type 2 diabetes mellitus. World J Gastroenterol 2015;21:9607-13.

100. Shah RV, Allison MA, Lima JA, et al. Liver fat, statin use, and incident diabetes: The Multi-ethnic study of atherosclerosis. Atherosclerosis 2015;242:211-7.

101. Fukuda T, Hamaguchi M, Kojima T, et al. The impact of non-alcoholic fatty liver disease on incident type 2 diabetes mellitus in nonoverweight individuals. Liver Int 2016;36:275-83.

102. Chen GY, Cao HX, Li F, et al. New risk-scoring system including non-alcoholic fatty liver disease for predicting incident type 2 diabetes in East China: Shanghai Baosteel Cohort. J Diabetes Investig 2016;7:206-11.

103. Li Y, Wang J, Tang Y, et al. Bidirectional association between nonalcoholic fatty liver disease and type 2 diabetes in Chinese population: Evidence from the Dongfeng-Tongji cohort study. PLoS One 2017;12:e174291.

104. Ma J, Hwang SJ, Pedley A, et al. Bi-directional analysis between fatty liver and cardiovascular disease risk factors. $J$ Hepatol 2017;66:390-7.

105. Chen SC, Tsai SP, Jhao JY, Jiang WK, Tsao CK, Chang LY. Liver fat, hepatic enzymes, alkaline phosphatase and the risk of incident type 2 diabetes: a prospective study of 132,377 adults. Sci Rep 2017;7:4649.

106. Liu M, Wang J, Zeng J, Cao X, He Y. Association of NAFLD with diabetes and the impact of BMI changes: a 5-year cohort study based on 18,507 elderly. J Clin Endocrinol Metab 2017;102:1309-16.

107. Mantovani A, Byrne CD, Bonora E, Targher G. Nonalcoholic fatty liver disease and risk of incident type 2 diabetes: a meta-analysis. Diabetes Care 2018;41:372-82.

108. Mantovani A, Petracca G, Beatrice G, Tilg H, Byrne CD, Targher G. Non-alcoholic fatty liver disease and risk of incident diabetes mellitus: an updated meta-analysis of 501022 adult individuals. Gut 2020:gutjnl-2020-322572.

109. Sung KC, Wild SH, Byrne CD. Resolution of fatty liver and risk of incident diabetes. J Clin Endocrinol Metab 2013;98:3637-43.

110. Cho HJ, Hwang S, Park JI, et al. Improvement of nonalcoholic fatty liver disease reduces the risk of type 2 diabetes mellitus. Gut Liver 2019;13:440-9.

111. Heo NY. Nonalcoholic fatty liver disease is a stepping stone in the path toward diabetes mellitus. Gut Liver 2019;13:383-4.

112. Mauvais-jarvis F, Bairey Merz N, Barnes PJ, et al. Sex and gender: modifiers of health, disease, and medicine. Lancet 2020;396:565-82.

113. Lonardo A, Nascimbeni F, Ballestri S, et al. Sex differences in nonalcoholic fatty liver disease: state of the art and identification of research gaps. Hepatology 2019;70:1457-69.

114. Rinella ME. Nonalcoholic fatty liver disease: a systematic review. JAMA 2015;313:2263-73.

115. de Marco R, Locatelli F, Zoppini G, Verlato G, Bonora E, Muggeo M. Cause-specific mortality in type 2 diabetes. The Verona Diabetes Study. Diabetes Care 1999;22:756-61.

116. Zoppini G, Fedeli U, Gennaro N, Saugo M, Targher G, Bonora E. Mortality from chronic liver diseases in diabetes. Am J Gastroenterol 2014;109:1020-5.

117. Adams LA, Harmsen S, St Sauver JL, et al. Nonalcoholic fatty liver disease increases risk of death among patients with diabetes: a community-based cohort study. Am J Gastroenterol 2010;105:1567-73.

118. Elkrief L, Rautou PE, Sarin S, Valla D, Paradis V, Moreau R. Diabetes mellitus in patients with cirrhosis: clinical implications and management. Liver Int 2016;36:936-48.

119. Bertot LC, Jeffrey GP, de Boer B, et al. Diabetes impacts prediction of cirrhosis and prognosis by non-invasive fibrosis models in nonalcoholic fatty liver disease. Liver Int 2018;38:1793-802.

120. de Lédinghen V, Vergniol J, Gonzalez C, et al. Screening for liver fibrosis by using FibroScan( $\left({ }^{\circledR}\right)$ and FibroTest in patients with diabetes. Dig Liver Dis 2012;44:413-8.

121. Sanyal A, Poklepovic A, Moyneur E, Barghout V. Population-based risk factors and resource utilization for HCC: US perspective. Curr Med Res Opin 2010;26:2183-91.

122. Ertle J, Dechêne A, Sowa JP, et al. Non-alcoholic fatty liver disease progresses to hepatocellular carcinoma in the absence of apparent cirrhosis. Int J Cancer 2011;128:2436-43.

123. Targher G, Bertolini L, Padovani R, et al. Prevalence of nonalcoholic fatty liver disease and its association with cardiovascular disease among type 2 diabetic patients. Diabetes Care 2007;30:1212-8.

124. Cassidy S, Hallsworth K, Thoma C, et al. Cardiac structure and function are altered in type 2 diabetes and non-alcoholic fatty liver disease and associate with glycemic control. Cardiovasc Diabetol 2015;14:23.

125. Mantovani A, Pernigo M, Bergamini C, et al. Heart valve calcification in patients with type 2 diabetes and nonalcoholic fatty liver disease. Metabolism 2015;64:879-87.

126. Targher G, Valbusa F, Bonapace S, et al. Association of nonalcoholic fatty liver disease with QTc interval in patients with type 2 diabetes. Nutr Metab Cardiovasc Dis 2014;24:663-9.

127. Mantovani A, Rigolon R, Pichiri I, et al. Nonalcoholic fatty liver disease is associated with an increased risk of heart block in hospitalized patients with type 2 diabetes mellitus. PLoS One 2017;12:e0185459.

128. Polyzos SA, Mantzoros CS. Making progress in nonalcoholic fatty liver disease (NAFLD) as we are transitioning from the era of NAFLD to dys-metabolism associated fatty liver disease (DAFLD). Metabolism 2020;111S:154318. 
129. Mantovani A, Targher G. Type 2 diabetes mellitus and risk of hepatocellular carcinoma: spotlight on nonalcoholic fatty liver disease. Ann Transl Med 2017;5:270.

130. Wang P, Kang D, Cao W, Wang Y, Liu Z. Diabetes mellitus and risk of hepatocellular carcinoma: a systematic review and meta-analysis. Diabetes Metab Res Rev 2012;28:109-22.

131. Yang WS, Va P, Bray F, et al. The role of pre-existing diabetes mellitus on hepatocellular carcinoma occurrence and prognosis: a metaanalysis of prospective cohort studies. PLoS One 2011;6:e27326.

132. Petrick JL, Thistle JE, Zeleniuch-Jacquotte A, et al. Body mass index, diabetes and intrahepatic cholangiocarcinoma risk: the liver cancer pooling project and meta-analysis. Am J Gastroenterol 2018;113:1494-505.

133. Huang YJ, Wu AT, Chiou HY, et al. Interactive role of diabetes mellitus and female sex in the risk of cholangiocarcinoma: a populationbased nested case-control study. Oncotarget 2017;8:6642-51.

134. Anstee QM, Mantovani A, Tilg H, Targher G. Risk of cardiomyopathy and cardiac arrhythmias in patients with nonalcoholic fatty liver disease. Nat Rev Gastroenterol Hepatol 2018;15:425-39.

135. Younossi ZM, Koenig AB, Abdelatif D, Fazel Y, Henry L, Wymer M. Global epidemiology of nonalcoholic fatty liver disease-Metaanalytic assessment of prevalence, incidence, and outcomes. Hepatology 2016;64:73-84.

136. Paik JM, Henry L, De Avila L, Younossi E, Racila A, Younossi ZM. Mortality related to nonalcoholic fatty liver disease is increasing in the United States. Hepatol Commun 2019;3:1459-71.

137. Targher G, Byrne CD, Lonardo A, Zoppini G, Barbui C. Non-alcoholic fatty liver disease and risk of incident cardiovascular disease: a meta-analysis. J Hepatol 2016;65:589-600.

138. Meyersohn NM, Mayrhofer T, Corey KE, et al. Association of hepatic steatosis with major adverse cardiovascular events, independent of coronary artery disease. Clin Gastroenterol Hepatol 2020:S1542-3565(20)30992-7.

139. Mantovani A, Zoppini G, Targher G, Golia G, Bonora E. Non-alcoholic fatty liver disease is independently associated with left ventricular hypertrophy in hypertensive type 2 diabetic individuals. J Endocrinol Invest 2012;35:215-8.

140. Rossi A, Targher G, Zoppini G, et al. Aortic and mitral annular calcifications are predictive of all-cause and cardiovascular mortality in patients with type 2 diabetes. Diabetes Care 2012;35:1781-6.

141. Mantovani A, Dauriz M, Sandri D, et al. Association between non-alcoholic fatty liver disease and risk of atrial fibrillation in adult individuals: An updated meta-analysis. Liver Int 2019;39:758-69.

142. Mantovani A. Nonalcoholic fatty liver disease (NAFLD) and risk of cardiac arrhythmias: a new aspect of the liver-heart axis. $J$ Clin Transl Hepatol 2017;5:134-41.

143. Chalasani N, Younossi Z, Lavine JE, et al. The diagnosis and management of nonalcoholic fatty liver disease: practice guidance from the American Association for the Study of Liver Diseases. Hepatology 2018;67:328-57.

144. European Association for the Study of the Liver (EASL), European Association for the Study of Diabetes (EASD), European Association for the Study of Obesity (EASO). EASL-EASD-EASO Clinical Practice Guidelines for the management of non-alcoholic fatty liver disease. J Hepatol 2016;64:1388-402.

145. Byrne CD, Targher G. NAFLD as a driver of chronic kidney disease. J Hepatol 2020;72:785-801.

146. Jia G, Di F, Wang Q, et al. Non-Alcoholic fatty liver disease is a risk factor for the development of diabetic nephropathy in patients with type 2 diabetes mellitus. PLoS One 2015;10:e0142808.

147. Nampoothiri RV, Duseja A, Rathi M, et al. Renal dysfunction in patients with nonalcoholic fatty liver disease is related to the presence of diabetes mellitus and severity of liver disease. J Clin Exp Hepatol 2019;9:22-8.

148. Mantovani A, Zusi C, Dalbeni A, Grani G, Buzzetti E. Risk of kidney dysfunction in NAFLD. Curr Pharm Des 2020;26:1045-61.

149. Targher G, Chonchol M, Bertolini L, et al. Increased risk of CKD among type 2 diabetics with nonalcoholic fatty liver disease. $J$ Am Soc Nephrol 2008;19:1564-70.

150. Mantovani A, Zaza G, Byrne CD, et al. Nonalcoholic fatty liver disease increases risk of incident chronic kidney disease: A systematic review and meta-analysis. Metabolism 2018;79:64-76.

151. Paik J, Golabi P, Younoszai Z, Mishra A, Trimble G, Younossi ZM. Chronic kidney disease is independently associated with increased mortality in patients with nonalcoholic fatty liver disease. Liver Int 2019;39:342-52.

152. Önnerhag K, Dreja K, Nilsson PM, Lindgren S. Increased mortality in non-alcoholic fatty liver disease with chronic kidney disease is explained by metabolic comorbidities. Clin Res Hepatol Gastroenterol 2019;43:542-50.

153. Mantovani A, Taliento A, Zusi C, et al. PNPLA3 I148M gene variant and chronic kidney disease in type 2 diabetic patients with NAFLD: Clinical and experimental findings. Liver Int 2020;40:1130-41.

154. Lv WS, Sun RX, Gao YY, et al. Nonalcoholic fatty liver disease and microvascular complications in type 2 diabetes. World $J$ Gastroenterol 2013;19:3134-42.

155. Kim BY, Jung CH, Mok JO, Kang SK, Kim CH. Prevalences of diabetic retinopathy and nephropathy are lower in Korean type 2 diabetic patients with non-alcoholic fatty liver disease. J Diabetes Investig 2014;5:170-5.

156. Asrih M, Jornayvaz FR. Metabolic syndrome and nonalcoholic fatty liver disease: is insulin resistance the link? Mol Cell Endocrinol 2015;418 Pt 1:55-65.

157. Miele L, Valenza V, La Torre G, et al. Increased intestinal permeability and tight junction alterations in nonalcoholic fatty liver disease. Hepatology 2009;49:1877-87.

158. Beserra BT, Fernandes R, do Rosario VA, Mocellin MC, Kuntz MG, Trindade EB. A systematic review and meta-analysis of the prebiotics and synbiotics effects on glycaemia, insulin concentrations and lipid parameters in adult patients with overweight or obesity. Clin Nutr 2015;34:845-58. 
159. Randrianarisoa E, Lehn-Stefan A, Wang X, et al. Relationship of serum trimethylamine N-oxide (TMAO) levels with early atherosclerosis in humans. Sci Rep 2016;6:26745.

160. Khurana S, Raufman JP, Pallone TL. Bile acids regulate cardiovascular function. Clin Transl Sci 2011;4:210-8.

161. Semenkovich CF. Insulin resistance and atherosclerosis. J Clin Invest 2006;116:1813-22.

162. Malehmir M, Pfister D, Gallage S, et al. Platelet GPIb $\alpha$ is a mediator and potential interventional target for NASH and subsequent liver cancer. Nat Med 2019;25:641-55. 